\title{
Minho Affective Sentences (MAS): Probing the roles of sex, mood, and empathy in affective ratings of verbal stimuli
}

\author{
Ana P. Pinheiro ${ }^{1,2} \cdot$ Marcelo Dias $^{1} \cdot$ João Pedrosa $^{1}$ • Ana P. Soares ${ }^{3}$
}

Published online: 22 March 2016

(C) Psychonomic Society, Inc. 2016

\begin{abstract}
During social communication, words and sentences play a critical role in the expression of emotional meaning. The Minho Affective Sentences (MAS) were developed to respond to the lack of a standardized sentence battery with normative affective ratings: 192 neutral, positive, and negative declarative sentences were strictly controlled for psycholinguistic variables such as numbers of words and letters and per-million word frequency. The sentences were designed to represent examples of each of the five basic emotions (anger, sadness, disgust, fear, and happiness) and of neutral situations. These sentences were presented to 536 participants who rated the stimuli using both dimensional and categorical measures of emotions. Sex differences were also explored. Additionally, we probed how personality, empathy, and mood from a subset of 40 participants modulated the affective ratings. Our results confirmed that the MAS affective norms are valid measures to guide the selection of stimuli for experimental studies of emotion. The combination of dimensional and categorical ratings provided a more finegrained characterization of the affective properties of the sentences. Moreover, the affective ratings of positive and
\end{abstract}

Electronic supplementary material The online version of this article (doi:10.3758/s13428-016-0726-0) contains supplementary material, which is available to authorized users.

Ana P. Pinheiro

ana.pinheiro@psi.uminho.pt

1 Neuropsychophysiology Lab, CIPsi, School of Psychology, University of Minho, Minho, Portugal

2 Faculty of Psychology, University of Lisbon, Lisbon, Portugal

3 Human Cognition Lab, School of Psychology, University of Minho, Minho, Portugal negative sentences were not only modulated by participants' sex, but also by individual differences in empathy and mood state. Together, our results indicate that, in their quest to reveal the neurofunctional underpinnings of verbal emotional processing, researchers should consider not only the role of sex, but also of interindividual differences in empathy and mood states, in responses to the emotional meaning of sentences.

Keywords Sentences $\cdot$ Affective ratings $\cdot$ Affective dimensions $\cdot$ Discrete emotions $\cdot$ Individual differences

Emotional information is an intrinsic part of social communication and social interactions. During social interactions, emotions are conveyed either by suprasegmental aspects of speech (e.g., prosody) and/or by the emotional semantic content of verbal expressions such as "I am feeling so excited" (e.g., Beaucousin et al., 2007; Pell, Jaywant, Monetta, \& Kotz, 2011). Facial expressions, voice modulations, gestures, and even posture may also effectively communicate emotions (e.g., Ekman, 1993; Juslin \& Laukka, 2003; Scherer, 1995; Wallbott, 1998). Therefore, listeners constantly face the challenge of effectively and rapidly decoding the affective states of social partners on the basis of verbal and nonverbal cues, to ensure success in social interactions (e.g., Frith \& Frith, 1999; Lopes et al., 2004).

In the last decades, robust evidence has accumulated showing that we are especially adept at and tuned to decode emotional information from numerous types of signals (e.g., Kousta, Vinson, \& Vigliocco, 2009; Liu et al., 2012; Pinheiro, del Re, Mezin, et al., 2013; Pinheiro et al., 2014). This is not surprising, considering the role played by the fast detection of emotional salience in approach versus avoidance behaviors, and its relevance for survival or attainment of goals. For example, listening to a pleasant birdsong in a garden with blooming flowers or being informed that "The 
garden is beautiful" may increase the tendency to approach such a place. Instead, listening to unexpected footstep sounds in the middle of the night or becoming aware that "The burglar is invading the house" may lead to a fight-or-flight (avoidance) response as a result of perceived danger. It is generally accepted that the detection of an emotionally salient stimulus may result in the activation of two distinct motivational systems: The defensive system is activated by threatrelated stimuli, and is associated with withdrawal or attack behaviors; the appetitive system is activated by stimuli that are related to well-being and survival, and is associated with approach behaviors (M. M. Bradley, Codispoti, Sabatinelli, \& Lang, 2001; M. M. Bradley \& Lang, 1994).

In spite of the vast number of studies dedicated to probing the behavioral and neural correlates of emotion, as well as to exploring its philosophical and social aspects (a current PubMed search revealed 193,089 published studies on this topic), there is not a consensual definition of emotion. Nondiscrete approaches propose that emotion derives from the evaluation of a stimulus or situation along a small number of dimensions (e.g., M. M. Bradley \& Lang, 2000; Russell, 2003). These dimensions include valence (the perceived pleasantness or unpleasantness of a stimulus or situation, ranging from unpleasant to pleasant), arousal (the degree of alertness or excitement elicited by the stimulus or situation, ranging from calm to arousing), and dominance (the degree of perceived control over the stimulus or situation, ranging from controlled to in control) (e.g., Bradley \& Lang, 1994, 2000; Osgood, Suci, \& Tannenbaum, 1957). These dimensions have been often assessed using a 9-point nonverbal pictographic self-report measure-the Self-Assessment Manikin (SAM; M. M. Bradley \& Lang, 1994). This approach may be better suited to characterize stimuli for which it is difficult to attribute a primary emotional category (Kanske \& Kotz, 2011). Recent studies also suggest that the representations of different affective dimensions rely on distinct cognitive and neural substrates (e.g., Dresler, Mériau, Heekeren, \& van der Meer, 2009). For example, whereas the amygdala tends to respond more intensely as a function of stimulus arousal, the prefrontal cortex seems to be more sensitive to the valence of the stimulus (e.g., Kensinger \& Schacter, 2006; Lewis, Critchley, Rotshtein, \& Dolan, 2007; Posner et al., 2009).

On the other hand, discrete approaches to emotion propose the existence of discrete affective categories, which are triggered by specific conditions, elicit specific behavioral and biological patterns, and are considered more or less universal (e.g., Ekman, 1992; LeDoux, 1996; Öhman \& Wiens, 2004; Scherer \& Ellgring, 2007). Most supporters of this account agree that at least five basic emotions should be considered: anger, happiness, fear, sadness, and disgust (e.g., Ekman, 1992). In behavioral studies, these categories are typically assessed with forced choice identification tasks (in which participants are required to choose a specific emotional label, among other options, to better characterize a given stimulus), or with intensity scales (in which participants are instructed to rate the intensity of a given stimulus on several intensity scales representing different emotions). Studies probing discrete emotional categories have suggested that these categories have different neurobiological substrates, which cannot be explained by dimensional models (e.g., Buchanan et al., 2000; Grandjean et al., 2005; S. K. Scott et al., 1997).

Studies that have tested the predictive value of discrete categories on dimensional ratings (and vice versa) have demonstrated that the two types of assessments offer different information about the affective stimuli. For example, each discrete emotion may be identified by a specific set of coordinates in the multidimensional affective space, such as valence and arousal (e.g., Stevenson \& James, 2008; Stevenson, Mikels, \& James, 2007; Wierzba et al., 2015). Additionally, the effects of categories on affective dimensions are heterogeneous, supporting the need to reconsider dimensional and categorical approaches as independent perspectives (e.g., Stevenson et al., 2007). Therefore, dimensional and discrete approaches are not mutually exclusive: When combined, they may provide complementary information, and both should be taken into account when conducting experimental studies of emotion (e.g., Christie \& Friedman, 2004; Russell, 2003; Stevenson \& James, 2008; Stevenson et al., 2007; Wierzba et al., 2015). Recognizing the advantages of the combination of dimensional and categorical accounts, with the present study we aimed to collect categorical and dimensional affective ratings for 192 European Portuguese sentences, to provide a deeper understanding of the emotional features of the stimuli under study. To the best of our knowledge, this is the first battery to present emotional ratings for sentences, which is surprising, considering the critical role that sentences play in the expression of emotional meaning during social communication.

In spite of the high number of studies investigating the behavioral and neurofunctional correlates of emotional verbal stimuli, most of these studies have used single words instead of sentences. These studies have demonstrated that words such as "stupid," "beautiful," or "round" are processed differently, even when they are task-irrelevant, and that neutral and emotional words are associated with distinct neurofunctional mechanisms. For example, as compared with neutral information, emotional words tend to attract more attention (e.g., Anderson, 2005; Dresler et al., 2009), to be remembered better (e.g., Hadley \& MacKay, 2006; Kensinger \& Corkin, 2003; Kissler, Herbert, Peyk, \& Junghofer, 2007; Monnier \& Syssau, 2008), and to be associated with enhanced source memory (Doerksen \& Shimamura, 2001) ${ }^{1}$ and faster reaction

\footnotetext{
${ }^{1}$ We note, however, that this is a controversial result (please see Chiu, Dolcos, Gonsalves, \& Cohen, 2013).
} 
times (e.g., G. G. Scott, O’Donnell, Leuthold, \& Sereno, 2009; Stormark, Nordby, \& Hugdahl, 1995). Support for the differential processing of neutral versus emotional words has also been provided by event-related potential (ERP) and functional neuroimaging studies. For example, ERPs have revealed early and later effects of emotionality, indexed, respectively, by enhanced early posterior negativity and late positive components to emotional relative to neutral words (e.g., Herbert, Junghofer, \& Kissler, 2008; Kissler et al., 2007; Kissler, Herbert, Winkler, \& Junghofer, 2009). The neutralemotional differentiation may already be observed within 100 ms after stimulus onset (G. G. Scott et al., 2009). Faster processing of emotional words, reflected in earlier latency effects, has also been demonstrated (Schacht \& Sommer, 2009). Some studies have shown a processing advantage for pleasant words, in support of a positivity offset account (e.g., Herbert et al., 2008; Palazova, Mantwill, Sommer, \& Schacht, 2011). Furthermore, neuroimaging studies have shown that, compared to neutral words, emotional words elicit increased activation in the amygdala (e.g., Kensinger \& Schacter, 2006; Lewis et al., 2007), in the left orbitofrontal gyrus and bilateral inferior frontal gyrus (Kuchinke et al., 2005), or in the left subgenual cingulate cortex (Maddock, Buonocore, Kile, $\&$ Garrett, 2003). Other studies have demonstrated that discrete emotion information (e.g., sadness) affects the processing of single words earlier than do broader affective dimensions (e.g., negativity). For example, Briesemeister, Kuchinke, and Jacobs (2014) found that the emotional category of words (happiness) affected the early N1 ERP component, whereas the valence of the words (positivity) affected later ERP components - an N400-like component and the late positive complex. Discrete categories and affective dimensions were also found to be dissociable in the brain, as suggested by different patterns of brain activation in response to, for example, happiness versus the overall positivity of words (Briesemeister, Kuchinke, Jacobs, \& Braun, 2015). Examples of standardized sets of single words include the Affective Norms for English Words (ANEW; M. M. Bradley \& Lang, 1999) and associated discrete norms (Stevenson et al., 2007), the Berlin Affective Word List (Võ et al., 2009) and associated discrete norms for nouns (e.g., DENN-BAWL; Briesemeister, Kuchinke, \& Jacobs, 2011), the Leipzig Affective Norms for German (Kanske \& Kotz, 2010), and the Nencki Affective Word List (Riegel et al., 2015).

The few studies that have probed emotional processing using more complex linguistic units have mainly focused on emotional prosody, relying on sentences with neutral semantic content and spoken with different emotional intonations (e.g., Kotz et al., 2003; Lima \& Castro, 2011; Lima, Garrett, \& Castro, 2013; Paulmann \& Kotz, 2008a, 2008b; Pinheiro, del Re, Mezin, et al., 2013; Pinheiro, Vasconcelos, Dias, Arrais, \& Gonçalves, 2015) or on pseudosentences (e.g., Paulmann \& Kotz, 2008a, 2008b; Pinheiro et al., 2015;
Pinheiro, del Re, Mezin, et al., 2013). Other studies have attempted to study affective processing in more natural contexts by embedding affective words in sentence contexts (e.g., Bayer, Sommer, \& Schacht, 2010; Delaney-Busch \& Kuperberg, 2013; Ding, Wang, \& Yang, 2014; Holt, Lynn, \& Kuperberg, 2009; Lüdtke \& Jacobs, 2015; MartínLoeches et al., 2012). More recently, the capacity to compute implied emotion in sentences has also been investigated (e.g., Lai, Willems, \& Hagoort, 2015; Willems, Clevis, \& Hagoort, 2011). This new line of research is especially important, considering that sentences represent more ecological stimuli than single words and provide contextual information that is critical for emotional meaning comprehension. However, standardized stimulus sets with normative values for affective sentences are needed. Indeed, emotion research has been hampered by the lack of stimuli controlled for both psycholinguistic and affective properties, and validated for a given cultural context. One of the greatest advantages of verbal stimuli is that they can be more precisely controlled for physical features (e.g., size) or frequency of occurrence in daily life (Kanske $\&$ Kotz, 2011). However, to the best of our knowledge, no normative ratings have been provided for affective sentences. The relevance of experimentally controlled sentences fits with recent attempts at using more natural approaches to language use (e.g., Lai et al., 2015; Willems et al., 2011). The simultaneous control of the valence, arousal, and dominance properties of sentences, as well as the accuracy in recognizing the underlying discrete categories, is crucial for experimental studies of verbal emotional processing, using behavioral and/or neuroscience methodologies. Therefore, a sentences battery stands out as a valuable resource for emotion research. It can be used, for example, to probe how semantic and prosodic types of information are integrated when they are congruent or incongruent (e.g., Wittfoth et al., 2010), or to probe the comprehension of emotional meaning in healthy subjects, in patients with brain lesions (e.g., Lalande, Braun, Charlebois, \& Whitaker, 1992), or in psychopathological disorders characterized by altered emotional processing, such as schizophrenia (e.g., Pinheiro, del Re, Mezin, et al., 2013; Pinheiro et al., 2014).

\section{The role of interindividual differences in the response to emotional verbal stimuli}

It is well known that individual responses to emotional stimuli, such as sentences, may vary across individuals. Evidence from emotion research lends support to sex differences in the processing of verbal emotional information (e.g., Hamann \& Canli, 2004), and particularly to a female advantage in emotion recognition (e.g., Hampson, van Anders, \& Mullin, 2006; Li, Yuan, \& Lin, 2008). Specifically, women tend to rate unpleasant words as more arousing and more unpleasant than do 
men (e.g., Kanske \& Kotz, 2012; Soares, Comesaña, Pinheiro, Simões, \& Frade, 2012). These studies suggest that the selection of experimental stimuli should consider sex-related affective norms (i.e., affective norms for female and male participants separately). Sex differences have also been demonstrated by studies probing either prosodic or semantic processes. Investigating the effects of emotional prosody on the processing of subsequently presented positive and negative words, Schirmer, Kotz, and Friederici (2002) found that the effects of prosodic primes on visual target words occurred earlier in women than in men. Using semantically related and unrelated word pairs, Wirth et al. (2007) provided evidence for deeper semantic analysis in female than in male participants, reflected in an earlier and longer N400 effect. These studies indicate that women and men differ in the ways they perceive verbal and emotional information.

Besides sex differences, it is coming to light that interindividual differences influence the perception and response to emotional stimuli, including words and sentences. For example, the emotional states of participants have been shown to modulate the processing of sentences: where positive mood leads to increased semantic activation, negative mood results in semantic inhibition (Federmeier, Kirson, Moreno, \& Kutas, 2001; Pinheiro, del Re, Nestor, et al., 2013). Moodcongruency effects were also observed, suggesting that individuals preferentially process emotional information that is congruent with their current mood state (e.g., Bower, 1981; Mayer, McCormick, \& Strong, 1995; Rusting, 1998). Along these lines, subclinical levels of anxiety and depression were also found to modulate the affective ratings of verbal stimuli (Kanske \& Kotz, 2012). Moreover, some evidence supports the modulatory role of personality traits and social orientation measures (i.e., interest and concern for other individuals) in the response to emotional stimuli (Schirmer et al., 2008). The Big Five model of personality traits has been widely accepted to account for broad individual differences in the social and emotional domains, organizing these differences in five categories: extraversion, neuroticism, conscientiousness, agreeableness, and openness to experience (e.g., McCrae \& Costa, 2008). Studies that have probed the links between personality and emotional processing indicate that personality dimensions associated with positive (e.g., extraversion) and negative (e.g., neuroticism) moods may effectively predict the processing and response to emotional information (e.g., B. P. Bradley \& Mogg, 1994; De Pascalis \& Speranza, 2000; Rusting \& Larsen, 1998). Whereas the behavioral inhibition system (e.g., neuroticism) is associated with the processing of unpleasant information, the behavioral approach system (e.g., extraversion) is associated with the processing of pleasant emotional information (e.g., Gomez \& Gomez, 2002). For example, levels of extraversion were positively associated with the amygdala response to happy faces (e.g., Canli, Sivers, Whitfield, Gotlib, \& Gabrieli, 2002), whereas neuroticism was positively associated with amygdala activation in response to film clips of snakes (Fischer, Tillfors, Furmark, \& Fredrikson, 2001). Therefore, it is expected that individuals preferentially process emotional stimuli that are congruent with their stable personality traits (trait-congruency effects; Rusting, 1998).

Furthermore, individual differences in empathy also seem to modulate the response to emotional stimuli. The empathy construct involves at least the capacities to feel what another person is feeling (affective dimension), to know what the other person is feeling (cognitive dimension), and to react to the experience of the other person (behavioral dimension; Decety \& Jackson, 2006; Derntl et al., 2010; ShamayTsoory, Aharon-Peretz, \& Perry, 2009). For example, Singer and collaborators (2004) demonstrated that, when viewing signals indicating that a loved one was experiencing pain, women with higher levels of empathy showed more activation in brain regions involved in the affective experience of pain than did women with lower empathy levels.

As such, the role of interindividual differences in influencing the response to affective sentences needs particular clarification. In an attempt to shed light on this research question, we additionally probed how interindividual differences in empathy, mood, and personality influence the ways that affective sentences are assessed both dimensionally and categorically.

\section{The present studies and hypotheses}

In our first study, we probed how individuals rated the affective properties of sentences. To investigate this question, we designed a set of 192 simple neutral, positive, and negative declarative sentences - the Minho Affective Sentences (MAS), which were strictly controlled for psycholinguistic properties such as the numbers of words and letters in the sentence, and per million word frequency. The sentences were designed to represent examples of each of the five basic emotions (anger, sadness, disgust, fear, and happiness; Ekman, 1992) and of neutral situations. These sentences were presented to 536 participants who rated the stimuli using both dimensional and categorical measures of emotions. For the dimensional assessment, participants were instructed to rate the valence, arousal, and dominance of the sentences using the SAM scale. For the categorical assessment, they were instructed to rate the intensity of each sentence on six intensity scales: anger, sadness, disgust, fear, happiness, and neutrality. As in single-word datasets such as the ANEW, we hypothesized higher arousal, lower valence, and lower dominance ratings for negative than for positive and neutral sentences, and higher valence ratings for positive than for negative and neutral sentences (e.g., Soares et al., 2012). Also, we expected that sentences expressing a given emotion would be rated with higher intensity ratings in the corresponding emotion scale. 
Because previous studies had indicated that the effects of emotion categories on affective dimensional ratings are heterogeneous (i.e., each discrete category may influence affective dimensions in unique ways; Stevenson et al., 2007), we also hypothesized that the predictive value of each affective dimension (valence, arousal, or dominance) for the categorical ratings would differ as a function of the discrete emotion type (e.g., Stevenson et al., 2007).

On the basis of a robust body of evidence demonstrating differences between women and men in ratings of affective stimuli (e.g., Soares et al., 2012; Soares et al., 2013, 2015), we additionally probed the influence of participants' sex on the sentences evaluations. We expected differences in affective ratings between male and female participants. Specifically, we hypothesized that women would rate sentences as more arousing, and that they would use more extreme valence scores to rate affective sentences, particularly those expressing negative content, in keeping with previous studies on singleword affective ratings in Portuguese (e.g., Soares et al., 2012) and in other languages (e.g., Spanish; Redondo, Fraga, Padrón, \& Comesaña, 2007). We also expected increased intensity ratings on the scale reflecting the a priori MAS classification in female relative to male participants (e.g., Hampson et al., 2006; Li et al., 2008).

In our second study, we collected information regarding personality, empathy, and mood from a subset of 40 participants, to investigate whether and how the affective ratings of the sentences would be related to these interindividual measures. On the basis of previous findings (e.g., Schirmer et al., 2008), we hypothesized that personality traits such as extraversion (reflecting the tendency to approach other individuals and to be engaged in social interactions) or empathy levels (reflecting the capacity to adopt and understand somebody else's point of view) would be variables of interest for the present study, by modulating the ways that individuals would react to the MAS affective sentences. In addition, we hypothesized that the affective normative data would be influenced by the affective states of the participants at the time of the assessment (e.g., Pinheiro, del Re, Nestor, et al., 2013). Specifically, we expected that higher levels of extraversion would be associated with higher valence ratings of positive sentences, whereas neuroticism would be associated with lower valence ratings of negative sentences (e.g., B. P. Bradley \& Mogg, 1994; Canli et al., 2002; De Pascalis \& Speranza, 2000; Gomez \& Gomez, 2002; Rusting \& Larsen, 1998). Moreover, we hypothesized that higher empathy levels would be associated with more extreme valence scores (i.e., negative sentences would be rated as more unpleasant and positive sentences would be rated as more pleasant) and arousal ratings (i.e., emotional sentences would be rated as more arousing) (e.g., Singer et al., 2004).

Finally, we hypothesized that positive mood states would be associated with increased perceived pleasantness and arousal of the positive sentences. On the other hand, negative mood states would be associated with a bias for unpleasant or negative information, reflected in increased perceived unpleasantness and arousal of the negative sentences. This would be in line with observations of mood-congruency effects (e.g., Bower, 1981).

\section{Study 1: MAS dimensional and categorical norms}

The aim of our first study was to provide norms for dimensional (valence, arousal, and dominance) and categorical (intensity on five emotional scales and one neutral scale) ratings of 192 affective sentences. An additional goal was to probe whether and how female and male participants differed in the affective ratings of sentences. In addition, we aimed to test the predictive value of the affective dimensions on discrete ratings of the MAS sentences.

\section{Method}

Participants A sample of 536 European Portuguese healthy subjects (299 female, 237 male; mean age $=23.29$ years, $S D=$ 6.02, age range 14-64 years) participated in the experiment. All participants were European Portuguese native speakers and reported normal or corrected-to-normal visual acuity: $54.7 \%$ had completed 12 years of education, an additional $24.6 \%$ had a bachelor's degree, another $14.9 \%$ had a master's degree, $4.1 \%$ had completed only 9 years of education, and $1.7 \%$ had a $\mathrm{PhD}$ degree.

Participants whose responses were illustrative of nondiscriminative ratings or suggestive of inattention (e.g., repeatedly using the same values across dimensions to rate different sentences) were excluded from the total sample (nine were excluded and not considered for the analyses).

Stimuli A set of 192 sentences in European Portuguese was developed to represent five basic emotions (happiness, sadness, anger, fear, and disgust) and a sixth neutral (control) category. These sentences covered the six categories usually considered in emotion research. Overall, the sentences were intended to convey neutral $(n=64)$, positive $(n=64)$, or negative $(n=64)$ semantic content. Specifically, the positive sentences were designed to represent the emotion happiness, in line with the basic-emotions account (Ekman, 1992), and the negative sentences covered the four basic negative categories: anger $(n=16)$, fear $(n=16)$, disgust $(n=16)$, or sadness $(n=16)$. The affective content of the MAS sentences was previously assessed by two judges with expertise in language and emotion research. While creating these sentences, the authors focused on the simplicity and familiarity of their semantic content. All exemplars portrayed common daily activities and situations that were intentionally chosen to evoke specific 
emotional reactions (anger, fear, disgust, sadness, and happiness) and, additionally, the absence of emotion (neutral). Thus, the MAS corpus can be used across a broad range of populations (clinical and nonclinical) and age groups.

The sentences in each emotional category were matched for length (mean number of words and mean number of letters within words in the sentence) and per-million word frequency, considering the part of speech (PoS) of each word in the sentence, obtained from the Procura-PALavras lexical database (P-PAL; Soares et al., 2014, available at http://p-pal.di. uminho.pt/tools). Compound nouns were excluded. Table 1 illustrates the psycholinguistics characteristics of the MAS sentences by emotional category.

As expected, when comparing neutral, positive, and negative sentences, no differences were observed between the three MAS valence types in the mean number of words, $F(2,189)=$ $1.274, p>.05$, mean number of letters, $F(2,189)=5.474, p>$ .05 , or per-million word frequency, $F(2,189)=0.775, p>.05$. Similarly, when comparing the four negative categories (anger, fear, disgust, and sadness), no differences were observed regarding the mean number of words, $F(3,60)=0.916, p>$ .05 , mean number of letters, $F(3,60)=2.216, p>.05$, and mean word frequency, $F(3,60)=0.194, p>.05$. Thus, the different MAS sentence categories were equivalent in their underlying psycholinguistic properties, which is critical for avoiding potential confounds in the emotional ratings.

Procedure A Web survey procedure was used for data collection, due to advantages such as speed, accuracy, and low cost, and particularly the easy access provided to a larger number of participants (see, e.g., Couper, 2000). Data were collected using a website in HTML format that was specifically developed for this experiment, following the recommendations of Burke and James (2006): (1) clearly describing the aims of the research; (2) identifying the research team by providing e-mail contacts; (3) including clear instructions and informing about the estimated time to complete the survey; and (4) emphasizing privacy policy and data confidentiality. The experiment was advertised by e-mail or through the website of the research group (www.nerp-um.com). Students were given course credit for their participation. For the rest of the participants, a lottery of a gift voucher (value: $€ 50$ ) to a national bookstore chain was used as an incentive.

The online survey began with general and specific instructions for performing the experiment. Participants were also reminded about the volunteer nature of their participation and the confidentiality of the results. After providing sociodemographic information (age, educational level, and linguistic skills), participants had to rate a maximum of 28 neutral sentences, 28 positive sentences, and 28 negative sentences (representing the four negative categories - seven from each category), randomly selected from the full set of sentences (192). This was done to reduce fatigue and distraction. The order of the sentences was pseudorandomized across participants.

Participants were first asked to rate each sentence, in terms of valence (completely unpleasant to completely pleasant), arousal (completely calm to completely excited), and dominance (completely controlled by to completely in control), using the 9-point SAM scale (M.

Table 1 Psycholinguistic characterization of the MAS sentences, according to emotional category

\begin{tabular}{|c|c|c|c|c|c|c|c|}
\hline & \multicolumn{3}{|l|}{ MAS Sentences } & & & & \\
\hline & \multicolumn{3}{|l|}{ MAS Valence } & \multicolumn{4}{|c|}{ MAS Negative Category } \\
\hline & $\begin{array}{l}\text { Neutral } \\
(n=64)\end{array}$ & Positive $(n=64)$ & $\begin{array}{l}\text { Negative } \\
(n=64)\end{array}$ & Anger $(n=16)$ & Fear $(n=16)$ & Disgust $(n=16)$ & Sadness $(n=16)$ \\
\hline $\begin{array}{l}\text { Examples } \\
\quad \text { of } \\
\text { sentences }\end{array}$ & $\begin{array}{l}\text {-The building is } \\
\text { under } \\
\text { construction. } \\
\text { - The lady } \\
\text { bought flour. } \\
\text {-The ink is } \\
\text { blue. }\end{array}$ & $\begin{array}{l}\text {-The mother } \\
\text { hugged her son. } \\
\text {-The massage was } \\
\text { relaxing. } \\
\text { •Her dream was } \\
\text { accomplished. }\end{array}$ & & $\begin{array}{l}\text {-The boss } \\
\text { humiliated the } \\
\text { team. } \\
\text {-The guy is an } \\
\text { asshole. } \\
\text {-The seller cheated } \\
\text { on the client. }\end{array}$ & $\begin{array}{l}\text {-The killer chased } \\
\text { the victim. } \\
\text {-The criminals } \\
\text { spread the terror. } \\
\text {-The snake is } \\
\text { poisonous }\end{array}$ & $\begin{array}{l}\text {-The toilet is } \\
\text { filthy. } \\
\text {-The corpse is } \\
\text { decomposing. } \\
\text {-The lady touched } \\
\text { the feces. }\end{array}$ & $\begin{array}{l}\text {-The funeral is } \\
\text { tomorrow. } \\
\text {-The disease has no } \\
\text { cure. } \\
\text {-She had an } \\
\text { unhappy } \\
\text { marriage. }\end{array}$ \\
\hline $\begin{array}{c}\text { Number of } \\
\text { words }\end{array}$ & 4.78 & 4.66 & 4.74 & 4.88 & 4.75 & 4.69 & 4.63 \\
\hline $\begin{array}{l}\text { Number of } \\
\text { letters }\end{array}$ & 20.14 & 20.69 & 20.59 & 20.81 & 22.25 & 19.31 & 20 \\
\hline $\begin{array}{l}\text { Frequency } \\
\text { per } \\
\text { million }\end{array}$ & $7,690.62$ & $7,189.39$ & $7,386.06$ & $7,590.16$ & $7,293.56$ & $7,089.48$ & $7,571.04$ \\
\hline
\end{tabular}

Frequency was computed as the sum of the per million word frequencies of all the words included in a sentence (sensitive to the PoS), divided by the number of words in that sentence 
M. Bradley \& Lang, 1994). After rating the three affective dimensions (valence, arousal, and dominance) using the SAM, participants were asked to rate the intensity of each sentence in six emotional categories (anger, fear, disgust, sadness, happiness, and neutrality) using a 5-point intensity scale, ranging from (1) low intensity to (5) high intensity (following Stevenson et al., 2007). The order of the tasks (dimensional and categorical assessments) was the same for all participants, following previous studies that had implemented dimensional and categorical stimulus ratings (e.g., Belin, Fillion-Bilodeau, \& Gosselin, 2008). Examples of the sentences (not used in the experiment) were provided at the beginning of each assessment, to help participants get familiarized with the rating procedure and the scales. Participants were not only reminded that a personal, subjective rating was required (and, therefore, that there were not correct or false answers), but also encouraged to rate the sentences according to their first impressions. During the assessment, each sentence remained at the center of the computer screen until a response was made. Sentences were presented in Arial 30point font. Participants used the numbers on the keyboard to indicate their response. Answers were automatically saved after the participant's response, and the next sentence was presented. No time limit was imposed, but participants were encouraged to answer as quickly as they could. On average, the procedure took about $30 \mathrm{~min}$ to complete. Each sentence in the dataset was rated by at least 97 participants $(M=122.88, S D=9.96$, range $=$ 97-145).

\section{Results}

In this first study, we aimed to collect normative values for the valence, arousal, dominance, and intensity of the MAS sentences. The norms for each of the 192 MAS sentences are presented in the supplemental materials. Mean values $(M)$ and standard deviations $(S D)$ for the valence, arousal, dominance, and intensity of each of the abovementioned categories are presented for each of the 192 sentences.

The mean values and $S D$ s for neutral, positive, and negative sentences, and for each negative category (anger, sadness, disgust, and fear) in the total sample, are provided in Table 2. Following the procedure adopted by singleword normative studies (e.g., ANEW; Soares et al., 2012), we also present means and $S D$ s for each sentence category considering female and male participants separately.

Dimensional assessment Figure 1 shows the bivariate distribution of valence and arousal ratings averaged across all participants. The distribution confirms the typical boomerangshaped distribution reported by previous studies that have probed affective ratings for verbal (e.g., M. M. Bradley \& Lang, 1999; Soares et al., 2012) and nonverbal (e.g., M. M. Bradley \& Lang, 2007; Lang, Bradley, \& Cuthbert, 2008; Soares et al., 2013, 2015) stimuli. Similarly to pictures (e.g., Soares et al., 2015), sounds (e.g., Soares et al., 2013), and words (e.g., Soares et al., 2012), sentences rated as either highly pleasant or highly unpleasant were simultaneously rated as more arousing. The quadratic relationship $\left(r_{\text {quad }}=.89, p\right.$ $<.001$ ) explained $78.8 \%$ of the variance. We also probed the relationships between valence and arousal in female and male participants separately. The percentage of variance explained by the quadratic relationship was higher in female $\left(r_{\text {quad }}=.90\right.$, $\left.p<.001, R^{2}=81.5 \%\right)$ than in male $\left(r_{\text {quad }}=.82, p<.001, R^{2}=\right.$ $66.4 \%)$ participants.

Using repeated measures analyses of variance (ANOVAs), we tested the effects of MAS sentence valence (neutral, positive, or negative, based on the a priori sentence classifications) on the valence, arousal, and dominance ratings. All

Table 2 Mean ratings of valence, arousal and dominance for each MAS sentence category in the total sample, and in female and male participants separately

\begin{tabular}{|c|c|c|c|c|c|c|c|c|c|c|}
\hline & & \multicolumn{9}{|c|}{ Affective Ratings } \\
\hline \multicolumn{2}{|c|}{ MAS Sentence Category } & \multicolumn{3}{|l|}{ Valence } & \multicolumn{3}{|l|}{ Arousal } & \multicolumn{3}{|l|}{ Dominance } \\
\hline & & All & Female & Male & All & Female & Male & All & Female & Male \\
\hline Neutral & & $5.20(0.55)$ & $5.20(0.57)$ & $5.21(0.52)$ & $3.88(1.45)$ & $3.97(1.42)$ & $3.76(1.48)$ & $5.73(1.50)$ & $5.61(1.44)$ & $5.88(1.57)$ \\
\hline Positive $^{\mathrm{a}}$ & & $7.30(0.90)$ & $7.50(0.82)$ & $7.05(0.94)$ & $4.95(1.67)$ & $4.91(1.75)$ & $5.01(1.57)$ & $6.51(1.42)$ & $6.55(1.44)$ & $6.46(1.40)$ \\
\hline Negative $^{b}$ & & $2.35(0.90)$ & $2.05(0.76)$ & $2.73(0.93)$ & $6.49(1.55)$ & $6.82(1.50)$ & $6.08(1.52)$ & $3.14(1.49)$ & $2.90(1.38)$ & $3.43(1.57)$ \\
\hline \multirow[t]{4}{*}{ Negative } & Anger & $2.21(1.08)$ & $2.00(0.95)$ & $2.47(1.19)$ & $6.70(1.78)$ & $6.94(1.70)$ & $6.40(1.84)$ & $3.05(1.79)$ & $2.90(1.72)$ & $3.24(1.86)$ \\
\hline & Fear & $2.65(1.21)$ & $2.28(1.07)$ & $3.12(1.21)$ & $6.85(1.76)$ & $7.20(1.65)$ & $6.41(1.80)$ & $2.96(1.73)$ & $2.68(1.58)$ & $3.33(1.84)$ \\
\hline & Disgust & $2.40(1.15)$ & $2.06(0.95)$ & $2.82(1.24)$ & $6.14(1.76)$ & $6.47(1.66)$ & $5.71(1.80)$ & $3.52(1.71)$ & $3.36(1.64)$ & $3.73(1.78)$ \\
\hline & Sadness & $2.13(1.07)$ & $1.83(0.90)$ & $2.50(1.15)$ & $6.30(1.87)$ & $6.67(1.85)$ & $5.83(1.79)$ & $3.00(1.73)$ & $2.66(1.57)$ & $3.43(1.83)$ \\
\hline
\end{tabular}

Values range from 1 to 9 and represent means and standard deviations $[M(S D)]$ for all sentences in each emotional category. ${ }^{\mathrm{a}}$ Positive sentences. ${ }^{\mathrm{b}}$ Average of all negative categories (anger, fear, disgust, and sadness). Values for the total sample are provided in the "All" column 


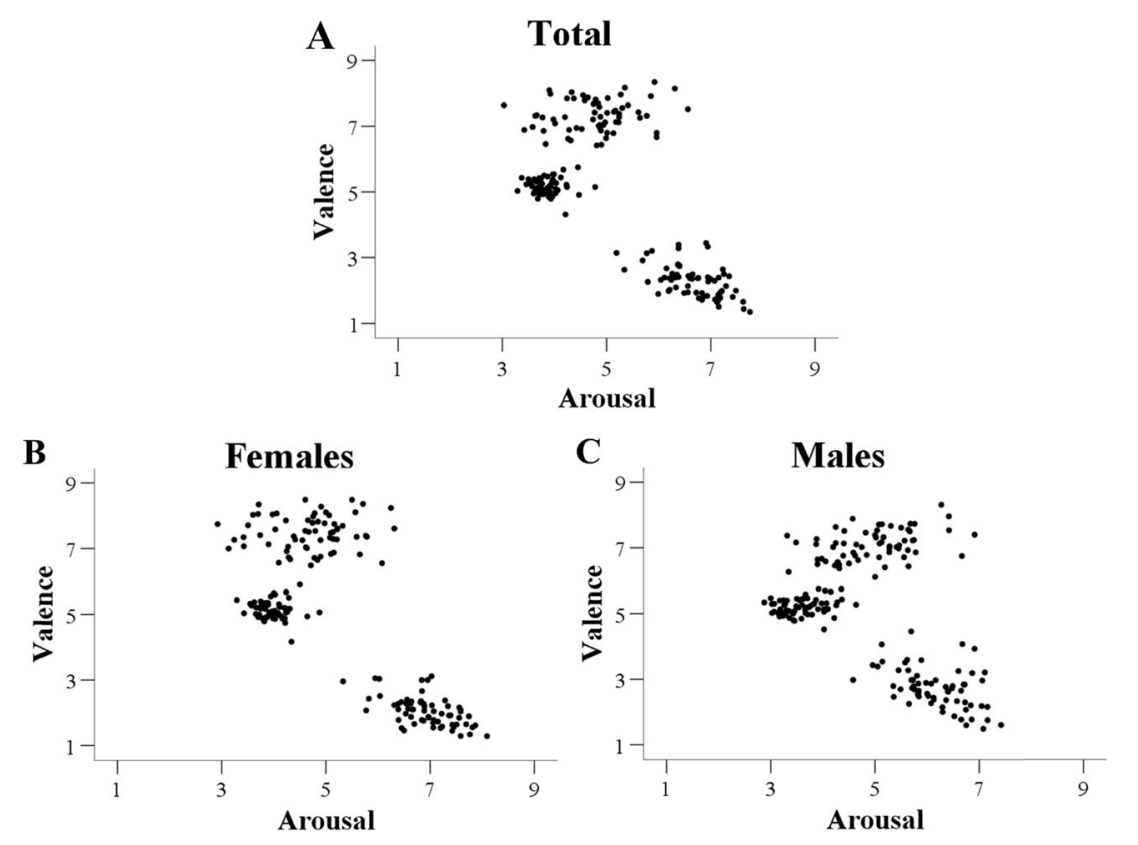

Fig. 1 Relationship between valence and arousal in the total sample (A), and in female (B) and male (C) participants separately

analyses using repeated measures ANOVA were corrected for nonsphericity using the Greenhouse-Geisser method (the original $d f$ is reported). All significance levels are two-tailed, with the present significance alpha level of $p<.05$. Main effects and interactions were followed by pairwise comparisons between conditions, using the Bonferroni adjustment for multiple comparisons. The SPSS 22.00 (SPSS Corp., USA) software package was used for the statistical analyses.

In a subsequent analysis, we tested the effects of negative category type on these dimensional ratings, considering the four negative categories separately, as each includes the same number of sentences $(n=16)$. For each analysis, participants' sex was added as a between-subjects factor to assess sex differences.

Valence Valence ratings differed as a function of MAS sentence valence (i.e., neutral, positive, or negative), $F(2,1070)=$ 4149.78, $p<.001, \eta_{\mathrm{p}}{ }^{2}=.886$ (Table 2). Planned pairwise comparisons revealed that positive sentences were rated as more pleasant than both neutral $(p<.001)$ and negative $(p<$ $.001)$ sentences, and that neutral sentences were rated as more pleasant than negative sentences $(p<.001)$. A significant interaction between valence and participant's sex, $F(2,1068)=$ $58.75, p<.001, \eta_{\mathrm{p}}{ }^{2}=.099$, indicated that negative sentences were rated as more negative $(p<.001)$ and positive sentences were rated as more positive $(p<.001)$ by female than by male participants, but the sexes did not differ in their valence ratings of neutral sentences $(p>.05)$.

In a second ANOVA testing the four negative categories only, a main effect of negative category indicated differences between anger, fear, disgust, and sadness sentences, $F(3$, $1605)=48.10, p<.001, \eta_{\mathrm{p}}{ }^{2}=.082$ (Table 2). Sentences expressing fear were rated as less unpleasant than sentences expressing disgust $(p<.001)$, anger $(p<.001)$, and sadness $(p$ $<.001)$, whereas sentences expressing disgust were rated as less unpleasant than sentences expressing anger $(p<.001)$ and sadness $(p<.001)$. Anger and sadness sentences did not differ in valence ratings $(p>.05)$, being perceived as more unpleasant than sentences expressing fear $(p<.001)$ and disgust $(p<$ $.001)$. A main effect of participant's sex, $F(1,534)=87.47, p$ $<.001, \eta_{\mathrm{p}}{ }^{2}=.141$, revealed that women rated all types of negative sentences as more unpleasant than did men.

Arousal The ANOVA comparing arousal ratings between neutral, positive, and negative sentences indicated a main effect of MAS sentence valence, $F(2,1070)=418.11, p<.001$, $\eta_{\mathrm{p}}{ }^{2}=.439$ (Table 2). Specifically, negative sentences were rated as more arousing than positive $(p<.001)$ and neutral $(p<.001)$ stimuli, whereas positive sentences were rated as more arousing than neutral sentences $(p<.001)$.

The second ANOVA comparing anger, fear, disgust, and sadness sentences revealed differences between the negative emotional categories, $F(3,1605)=54.88, p<.001, \eta_{\mathrm{p}}{ }^{2}=.093$ (Table 2): Both fear and anger sentences were perceived as more arousing than sadness $(p<.001)$ and disgust $(p<.001)$ sentences, whereas fear and anger sentences did not differ in arousal ratings $(p>.05)$. A significant main effect of participant's sex, $F(1,534)=31.42, p<.001, \eta_{\mathrm{p}}{ }^{2}=0.056$, indicated that women rated all types of negative sentences as more arousing than did men.

Dominance The ANOVA testing the effects of MAS sentence valence (neutral, positive, and negative) on dominance ratings yielded a significant effect of valence, $F(2,1070)=1,133.20$, 
$p<.001, \eta_{\mathrm{p}}{ }^{2}=.679$ (Table 2). Negative sentences were rated with the lowest dominance ratings when compared to both neutral $(p<.001)$ and positive $(p<.001)$ sentences; neutral sentences received lower dominance scores than positive sentences $(p<.001)$. The significant interaction between valence and participant's sex, $F(2,1068)=9.03, p<.001, \eta_{\mathrm{p}}{ }^{2}=$ .017 , showed that female participants used lower dominance ratings than did men when rating negative $(p<.001)$ and neutral sentences $(p=.037)$, but not with positive sentences $(p>.05)$.

In the second ANOVA, comparing the four negative categories, a main effect of sentence category, $F(3,1605)=33.74$, $p<.001, \eta_{\mathrm{p}}{ }^{2}=.059$ (Table 2), indicated that disgust sentences received higher dominance ratings than did anger, sadness, and fear sentences ( $p$ s $<.001$ for all comparisons). A main effect of participant's sex, $F(1,534)=17.44, p<.001, \eta_{\mathrm{p}}{ }^{2}=$ .032 , revealed that women rated all negative categories with lower dominance ratings than did men.

Categorical assessment Table 3 shows the mean intensity ratings for each sentence category in the six intensity scales.

To probe which intensity scale received the highest score in the assessment of each MAS category (neutral, happiness, anger, sadness, fear, and disgust) and to probe sex differences in intensity ratings, we ran a separate repeated measures ANOVA for each MAS category, with scale (neutral, happiness, anger, sadness, fear, or disgust) as a within-subjects factor and sex as a between-subjects factor.

Intensity ratings were the highest in the scale corresponding to the a priori MAS sentence classification (e.g., neutral intensity scale for neutral MAS sentences), as revealed by a main effect of scale: neutral, $F(5,2675)$ $=1,458.91, p<.001, \eta_{\mathrm{p}}{ }^{2}=.732(p \mathrm{~s}<.001$ for all comparisons); positive/happiness, $F(5,2675)=1,941.42, p<$ $.001, \eta_{\mathrm{p}}{ }^{2}=.784$ ( $p \mathrm{~s}<.001$ for all comparisons); anger, $F(5,2675)=559.51, p<.001, \eta_{\mathrm{p}}{ }^{2}=.586(p \mathrm{~s}<.001$ for all comparisons); fear, $F(5,2675)=607.00, p<.001, \eta_{\mathrm{p}}{ }^{2}$ $=.532(p \mathrm{~s}<.001$ for all comparisons); disgust, $F(5,2675)$ $=779.83, p<.001, \eta_{\mathrm{p}}{ }^{2}=.593$ ( $p \mathrm{~s}<.001$ for all comparisons); and sadness, $F(5,2675)=959.33, p<.001, \eta_{\mathrm{p}}{ }^{2}=$ .642 ( $p \mathrm{~s}<.001$ for all comparisons). Furthermore, with the exception of anger, a significant intensity scale and sex interaction indicated that female participants rated the sentences with higher intensity values on the scale corresponding to the a priori MAS classification, when compared with men [neutral, $F(5,2670)=8.53, p<$ $.002, \eta_{\mathrm{p}}{ }^{2}=.016$; positive/happiness, $F(5,2670)=16.77$, $p<.001, \eta_{\mathrm{p}}{ }^{2}=.030$; fear, $F(5,2670)=27.05, p<.001$, $\eta_{\mathrm{p}}{ }^{2}=.048$; disgust, $F(5,2670)=18.12, p<.001, \eta_{\mathrm{p}}{ }^{2}=$ .033 ; sadness, $\left.F(5,2670)=15.62, p<.001, \eta_{\mathrm{p}}{ }^{2}=.028\right]$.

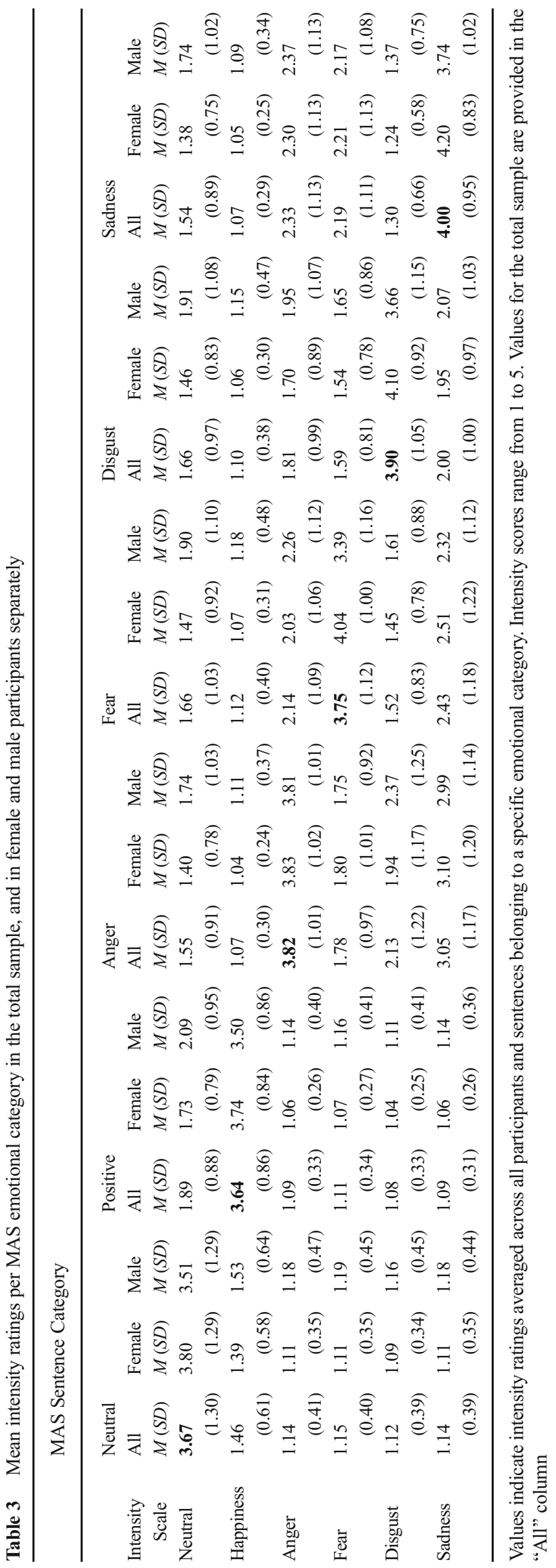


Relationship between dimensional and categorical ratings Multiple linear regressions were run to predict dimensional ratings from categorical intensity ratings, following Stevenson and collaborators (2007). This was done for neutral, positive, and negative sentences separately, and, subsequently, for the four types of negative categories (anger, fear, sadness, and disgust). Dimensional ratings were taken as predictors, and the dependent variable was the intensity ratings for each MAS category on the corresponding intensity scale. Table 4 shows standardized $\beta$ coefficients for the three affective dimensions.

The regressions showed that the categorical intensity ratings were significantly predicted by the three affective dimensions. This was the case for neutral sentences, $F(3,188)=$ 188.332, $p<.001, R^{2}=.750$; positive sentences, $F(3,188)$ $=817.507, p<.001, R^{2}=.929 ;$ and negative sentences, $F(3$, $188)=927.942, p<.001, R^{2}=.937$. This was also observed for all types of negative categories: anger, $F(3,188)=96.303$, $p<.001, R^{2}=.606$; disgust, $F(3,188)=43.102, p<.001, R^{2}=$ .408 ; sadness, $F(3,188)=165.627, p<.001, R^{2}=.725$; and fear, $F(3,188)=104.919, p<.001, R^{2}=.626$. However, in the cases of anger and happiness, dominance did not add statistically significantly to the prediction $(p>.05)$; in the case of sadness, valence did not add statistically significantly to the prediction $(p>.05)$; in the case of fear, arousal did not add statistically significantly to the prediction $(p>.05)$.

\section{Interim summary}

The results from Study 1 provided support for the a priori MAS classifications and indicated that the sentences from each category were reliably distinguished in both the dimensional and categorical ratings. They additionally revealed that women and men reacted differently to the affective sentences. Specifically, women used more extreme valence scores, rating negative sentences as more unpleasant and positive sentences as more pleasant than did men. They also rated negative sentences as more arousing, and both negative and neutral sentences with lower dominance scores than did men. Furthermore, women judged the sentences as being more intense on the corresponding intensity scale, with the exception of anger.

\section{Study 2: Relationships between affective ratings and empathy, mood, and personality}

Considering the role played by differences in empathy, personality traits, and mood in modulating the response to emotionally salient stimuli (e.g., Canli et al., 2002; Federmeier et al., 2001; Fischer et al., 2001; Pinheiro, del Re, Nestor, et al., 2013; Schirmer et al., 2008; Singer et al., 2004), in our second study we probed the relationship between individual differences on these variables and the affective ratings of the MAS sentences. A subsample of 40 participants was selected from the original sample that had assessed the MAS sentences both dimensionally and categorically. These participants completed empathy, personality, and mood questionnaires. A correlational analysis tested the associations between these measures and the MAS affective ratings.

\section{Method}

Participants A subset of 40 participants from the original sample (20 female, 20 male; mean age $=21.88$ years, $S D=$ 3.22 , age range $18-30$ years) completed empathy, personality, and mood questionnaires (see Table 5). All participants provided written informed consent for the experimental protocol approved by a local Ethical Committee. The study was conducted according to the principles expressed in the Declaration of Helsinki.

Measures The NEO Five-Factor Inventory (NEO-FFI; Costa \& McCrae, 1992; adapted to European Portuguese by Magalhães et al., 2014), composed of 60 items, was used to assess five personality dimensions: conscientiousness,

Table 4 Regressions of dimensional ratings predicting discrete emotional categories

\begin{tabular}{|c|c|c|c|c|c|c|}
\hline & \multicolumn{2}{|c|}{ Valence } & \multicolumn{2}{|c|}{ Arousal } & \multicolumn{2}{|c|}{ Dominance } \\
\hline & $\beta$ & $t$ & $\beta$ & $t$ & $\beta$ & $t$ \\
\hline Predicting neutrality & -.487 & $-6.125^{* * * *}$ & -.771 & $-12.665^{* * * *}$ & .369 & $2.781^{* *}$ \\
\hline Predicting happiness & .739 & $14.943^{* * * *}$ & .491 & $12.955^{* * *}$ & -.064 & -0.780 \\
\hline Predicting anger & -.208 & $-2.520^{*}$ & .308 & $4.876^{\text {**** }}$ & .063 & 0.461 \\
\hline Predicting disgust & -.617 & $-6.150^{* * * *}$ & .404 & $5.263^{* * * *}$ & .775 & $4.632^{* * *}$ \\
\hline Predicting fear & .400 & $5.127^{* * * *}$ & .020 & 0.338 & -.888 & $-6.832^{* * *}$ \\
\hline Predicting sadness & .004 & 0.044 & .169 & $2.747^{* * *}$ & -.428 & $-3.194^{* *}$ \\
\hline
\end{tabular}

$\beta$ values, $t$ scores, and significance levels are provided for each emotional dimension with respect to each emotional category. ${ }^{*} p<.05,{ }^{* * *} p<.01,{ }^{* * *} p<$ .001 . 
Table 5 Participants' scores on empathy (IRI), personality (NEOFFI), and mood (PANAS) assessments

\begin{tabular}{|c|c|c|c|c|}
\hline & \multirow[t]{2}{*}{ Measures } & \multicolumn{3}{|l|}{ Participants } \\
\hline & & $\begin{array}{l}\text { Total } \\
(N=40)\end{array}$ & $\begin{array}{l}\text { Women } \\
(N=20)\end{array}$ & $\begin{array}{l}\text { Men } \\
(N=20)\end{array}$ \\
\hline \multirow[t]{6}{*}{ Personality } & $N E O-F F I$ & & & \\
\hline & Neuroticism & $6.58(2.46)$ & $6.50(2.63)$ & $6.65(2.35)$ \\
\hline & Extraversion & $10.15(2.61)$ & $9.75(2.65)$ & $10.55(2.56)$ \\
\hline & Openness to experience & $8.76(4.00)$ & $7.20(3.67)$ & $10.35(3.77)$ \\
\hline & Agreeableness & $10.58(2.72)$ & $10.85(2.76)$ & $10.30(2.72)$ \\
\hline & Conscientiousness & $11.50(1.57)$ & $11.25(1.62)$ & $11.75(1.52)$ \\
\hline \multirow[t]{5}{*}{ Empathy } & $I R I$ & & & \\
\hline & Perspective taking & $2.88(0.56)$ & $2.96(0.51)$ & $2.81(0.61)$ \\
\hline & Empathic concern & $2.97(0.68)$ & $3.38(0.39)$ & $2.57(0.67)$ \\
\hline & Personal discomfort & $1.88(0.71)$ & $2.16(0.83)$ & $1.60(0.44)$ \\
\hline & Fantasy & $2.54(0.86)$ & $2.78(0.84)$ & $2.29(0.82)$ \\
\hline \multirow[t]{3}{*}{ Mood } & PANAS & & & \\
\hline & Positive affect & $21.80(6.31)$ & $20.25(5.60)$ & $23.35(6.72)$ \\
\hline & Negative affect & $12.45(4.60)$ & $13.20(4.58)$ & $11.70(4.61)$ \\
\hline
\end{tabular}

$M($ and $S D)$ values are shown extraversion, neuroticism, openness to experience, and agreeableness. This inventory has been consistently used in different cultural contexts to assess personality (e.g., Costa \& Mccrae, 1994; Costa, Terracciano, \& McCrae, 2001; McCrae et al., 1999). The Portuguese adaptation of the NEO-FFI revealed high levels of internal consistency and supported its validity and reliability (Magalhães et al., 2014).

The interpersonal reactivity index (IRI; Davis, 1983; adapted by Limpo, Alves, \& Castro, 2010) was used to measure empathy. The IRI is based on a multidimensional perspective of empathy. As such, this index is composed of four subscales: perspective taking (i.e., the tendency to adopt somebody else's perspective), empathic concern (i.e., the tendency to experience compassion and concern for others), personal discomfort (i.e., experience of anxiety and discomfort in tense interpersonal contexts), and fantasy (i.e., the tendency to imagine oneself in fictional situations). The IRI is one of the most widely used measures to assess empathy (e.g., Cliffordson, 2001; Haker \& Rössler, 2009; Raposo, Vicens, Clithero, Dobbins, \& Huettel, 2011). The validation to Portuguese confirmed the adequate internal consistency and good reliability of this instrument in the assessment of empathy (Limpo et al., 2010).

The Positive and Negative Affect Schedule (PANAS) was used to assess the participants' current mood state (Watson \& Tellegen, 1985; adapted by Galinha \& Ribeiro, 2005). The PANAS has been widely used in emotion and mood research (e.g., Brown, Chorpita, \& Barlow, 1998; Crawford \& Henry, 2004; Fredrickson \& Joiner, 2002; Ostir, Smith, Smith, \& Ottenbacher, 2005). It includes ten adjectives covering positive mood (e.g., "excited," "aroused") and ten adjectives covering negative mood states (e.g., "nervous," "scared"). Participants indicate the extent to which they have felt each emotion during the past two weeks. Higher scores reflect higher positive and/or negative affect.

Procedure Participants were tested individually. First, they rated the valence, arousal, dominance, and intensity of the 192 sentences (Study 1). After, they were asked to complete the empathy (IRI), personality (NEO-FFI), and mood (PANAS) questionnaires.

\section{Results}

First, we tested whether male and female participants differed in personality (five factors-conscientiousness, extraversion, neuroticism, openness to experience, and agreeableness), empathy (four subscales - perspective taking, empathic concern, personal discomfort, and fantasy), and mood (two dimensions - positive and negative affect) scores. Independent-sample $t$ tests were conducted to probe sex differences. Empathic concern (IRI) was higher in female than in male participants, $t(38)=-4.666, p<$ .001 , as was personal discomfort (IRI), $t(38)=2.678, p=$ .013 . No other sex differences were observed $(p>.05)$. On the basis of these findings, correlations were tested in the total sample for all measures, with the exception of empathic concern and personal discomfort: For these variables, the association with affective ratings was tested in female and male participants separately. Pearson's $r$ 
correlation coefficient was calculated, to test the relationships between affective ratings (valence, arousal, dominance, and intensity) ${ }^{2}$ and empathy, personality, and mood scores.

Personality measures were not significantly associated with the affective ratings $(p>.05)$. Furthermore, no significant association was found between ratings of neutral sentences and the individual measures $(p>.05)$. The Pearson's $r$ coefficients describing the associations between the ratings of positive and negative sentences and the empathy and mood scores are presented in Table $6 .^{3}$

Positive sentences When considering the total sample, increased valence $(p=.035)$ and intensity $(p=.024)$ scores were associated with higher IRI perspective taking. Furthermore, increased arousal ratings were associated with higher positive affect in the total sample $(p=.008)$. No significant correlations were observed for dominance ratings $(p>.05)$. In males only, increased valence scores were associated with higher IRI empathic concern $(p=.012)$. In females, no association was found between the affective ratings of positive sentences and either empathic concern or personal discomfort $(p>.05)$.

\section{Negative categories (anger, fear, sadness, and disgust)} When considering the four negative categories separately, we observed that increased empathy scores were associated with increased perceived unpleasantness and arousal of the distinct types of negative sentences in the total sample. Specifically, increased empathic perspective taking was associated with less pleasant $(p=.027)$ and more arousing ( $p=.036)$ ratings of sadness sentences.

In male participants, increased IRI empathic concern was associated with lower valence ratings $(p=.009)$ and higher arousal ratings ( $p=.005)$ of sadness sentences, and with lower valence ratings of fear sentences $(p=.04)$. In females, no association was found between affective ratings of the negative sentences and either empathic concern or personal discomfort $(p>.05)$.

\section{Interim summary}

The results from Study 2 indicated that empathy and mood, but not personality traits, modulated the affective ratings of positive and negative sentences only. Empathic concern and fantasy were higher in female than in male participants, but no sex differences were observed when contrasting the scores for the other variables.

\footnotetext{
${ }^{2}$ We considered the intensity ratings for each MAS category on the corresponding intensity scale.

${ }^{3}$ For the sake of simplicity and to avoid redundancy, we present data on the association between positive and the four types of negative sentences and the individual measures, but not between the mean ratings of negative sentences and the individual measures.
}

Overall, ratings of negative and positive sentences, but not of neutral sentences, were associated with differences in empathy and mood scores, when considering the total sample. In particular, in males only, the higher the empathic concern, the more unpleasant and arousing negative sentences were perceived to be, and the more pleasant positive sentences were perceived to be.

\section{General discussion}

In the present study, we aimed to probe how the MAS sentences, designed to represent different emotions, are rated both dimensionally and categorically. An additional aim was to explore how sex and individual variables, such as personality, empathy, and mood, modulate the affective ratings of the MAS sentences. These norms provide a means to investigate the two approaches to emotion with a set of more ecologic verbal stimuli. Moreover, they corroborate the emotional potential of simple sentences (e.g., Lüdtke \& Jacobs, 2015) and, in particular, the observation that emotion may be derived from word combinations in sentences (Lai et al., 2015).

Our first study confirmed that the affective norms of the MAS sentences are valid measures to guide the selection of stimuli for experimental studies of emotion. The dimensional results corroborated the a priori sentence categorizations: negative sentences (e.g., "The boss humiliated the team") were classified as the most unpleasant and arousing verbal stimuli, whereas positive sentences (e.g., "The actor is hilarious") were classified as the most pleasant verbal stimuli. In addition, we confirmed a tendency previously observed when investigating the affective ratings of pictures (e.g., Soares et al., 2015), sounds (e.g., Soares et al., 2013), and single words (e.g., Soares et al., 2012): the quadratic function underlying valence and arousal ratings indicated that highly pleasant and unpleasant sentences were more likely to be rated as highly arousing. This finding demonstrates the comparability of the present findings to previously published affective norms for single words, pictures, and sounds (e.g., M. M. Bradley \& Lang, 1999; Grühn \& Scheibe, 2008; Moors et al., 2013; Redondo et al., 2007; Soares et al., 2012; Soares et al., 2013, 2015; Võ et al., 2009; Warriner, Kuperman, \& Brysbaert, 2013).

Our results for the discrete assessment revealed that all sentences were classified with the highest intensity scores on the scale corresponding to the a priori sentence classification (e.g., positive sentences received the highest intensity ratings on the happiness scale). Both dimensional and categorical ratings indicated that neutral (e.g., "The ink is blue") and emotional (e.g., "The garden is beautiful") sentences are reliably distinguished, and suggested that these sentences are effective stimuli that can be used in experimental research 
Table 6 Correlations between affective ratings of the positive and negative sentences and participants' empathy and mood scores

\begin{tabular}{|c|c|c|c|c|c|c|c|c|c|}
\hline \multirow[t]{2}{*}{ Sentence } & \multirow{2}{*}{$\begin{array}{l}\text { Affective } \\
\text { Ratings }\end{array}$} & \multicolumn{8}{|c|}{ Interindividual Differences } \\
\hline & & $\begin{array}{l}\text { IRI } \\
\text { Perspective } \\
\text { Taking }\end{array}$ & $\begin{array}{l}\text { IRI Empathic } \\
\text { Concern }\end{array}$ & $\begin{array}{l}\text { IRI Personal } \\
\text { Discomfort }\end{array}$ & $\begin{array}{l}\text { IRI } \\
\text { Fantasy }\end{array}$ & $\begin{array}{l}\text { NEO } \\
\text { Neuroticism }\end{array}$ & $\begin{array}{l}\text { NEO } \\
\text { Extraversion }\end{array}$ & $\begin{array}{l}\text { PANAS } \\
\text { Positive Affect }\end{array}$ & $\begin{array}{l}\text { PANAS } \\
\text { Negative Affect }\end{array}$ \\
\hline \multirow[t]{4}{*}{$\begin{array}{l}\text { Positive / } \\
\text { Happiness }\end{array}$} & Valence & ALL: $.335^{*}$ & $\begin{array}{l}\text { M: .549* } \\
\text { F: }-.219\end{array}$ & $\begin{array}{l}\text { M: } .417 \\
\text { F: }-.015\end{array}$ & $\begin{array}{l}\text { ALL: } \\
.251\end{array}$ & ALL: .081 & ALL: -.093 & -.044 & -.130 \\
\hline & Arousal & ALL: -.087 & $\begin{array}{l}\text { M: } .153 \\
\text { F: } .301\end{array}$ & $\begin{array}{l}\text { M: } .190 \\
\text { F: } .230\end{array}$ & $\begin{array}{l}\text { ALL: } \\
\quad .105\end{array}$ & ALL: .087 & ALL: .257 & ALL: .411 ${ }^{* *}$ & ALL: .134 \\
\hline & Dominance & ALL: .085 & $\begin{array}{l}\text { M: .285 } \\
\text { F: }-.173\end{array}$ & $\begin{array}{l}\text { M: }-.190 \\
\text { F: } .089\end{array}$ & $\begin{array}{l}\text { ALL: } \\
-.146\end{array}$ & ALL: .094 & ALL: -.163 & ALL: -.091 & ALL: .074 \\
\hline & Intensity & ALL: . 356 ${ }^{*}$ & $\begin{array}{l}\text { M: } .165 \\
\text { F: }-.433\end{array}$ & $\begin{array}{l}\text { M: } .165 \\
\text { F: .127 }\end{array}$ & $\begin{array}{l}\text { ALL: } \\
\quad .246\end{array}$ & ALL: .110 & ALL: -.140 & ALL: -.070 & ALL: .000 \\
\hline \multirow[t]{4}{*}{ Anger } & Valence & ALL: -.272 & $\begin{array}{l}\text { M: }-.386 \\
\text { F: } .017\end{array}$ & $\begin{array}{l}\text { M: }-.407 \\
\text { F: } .204\end{array}$ & $\begin{array}{l}\text { ALL: } \\
\quad .011\end{array}$ & ALL: .001 & ALL: -.013 & ALL: - .006 & ALL: .144 \\
\hline & Arousal & ALL: .117 & $\begin{array}{l}\text { M: } .382 \\
\text { F: } .098\end{array}$ & $\begin{array}{l}\text { M: } .168 \\
\text { F: }-.041\end{array}$ & $\begin{array}{l}\text { ALL: } \\
-.071\end{array}$ & ALL: .093 & ALL: .024 & ALL: -.053 & ALL: .239 \\
\hline & Dominance & ALL: -.134 & $\begin{array}{l}\text { M: } .066 \\
\text { F: }-.049\end{array}$ & $\begin{array}{l}\text { M: }-.125 \\
\text { F: } .179\end{array}$ & $\begin{array}{l}\text { ALL: } \\
.198\end{array}$ & ALL: .196 & ALL: .041 & ALL: -.196 & ALL: .177 \\
\hline & Intensity & ALL: -.237 & $\begin{array}{l}\text { M: }-.095 \\
\text { F: } .188\end{array}$ & $\begin{array}{l}\text { M: }-.133 \\
\text { F: }-.224\end{array}$ & $\begin{array}{l}\text { ALL: } \\
-.207\end{array}$ & ALL: .062 & ALL: .033 & ALL: -.001 & ALL: .318 \\
\hline \multirow[t]{4}{*}{ Fear } & Valence & ALL: -.296 & $\begin{array}{l}\text { M: }-. \mathbf{4 6 4} \\
\text { F: }-.001\end{array}$ & $\begin{array}{l}\text { M: }-.211 \\
\text { F: }-.154\end{array}$ & $\begin{array}{l}\text { ALL: } \\
\quad-.247\end{array}$ & ALL: -.041 & ALL: 137 & ALL: .040 & ALL: -.156 \\
\hline & Arousal & ALL: .298 & $\begin{array}{l}\text { M: } .340 \\
\text { F: } .239\end{array}$ & $\begin{array}{l}\text { M: } .230 \\
\text { F: } .054\end{array}$ & $\begin{array}{l}\text { ALL: } \\
\quad .142\end{array}$ & ALL: .090 & ALL: -.006 & ALL: -.187 & ALL: .216 \\
\hline & Dominance & ALL: -.266 & $\begin{array}{l}\text { M: }-.003 \\
\text { F: }-.207\end{array}$ & $\begin{array}{l}\text { M: }-.187 \\
\text { F: }-.111\end{array}$ & $\begin{array}{l}\text { ALL: } \\
\quad .011\end{array}$ & ALL: -.009 & ALL: .134 & ALL: -.007 & ALL: .004 \\
\hline & Intensity & ALL: -.060 & $\begin{array}{l}\text { M: } .208 \\
\text { F: }-.299\end{array}$ & $\begin{array}{l}\text { M: } .288 \\
\text { F: } .277\end{array}$ & $\begin{array}{l}\text { ALL: } \\
\quad .149\end{array}$ & ALL: .141 & ALL: -.001 & ALL: .216 & ALL: .128 \\
\hline \multirow[t]{4}{*}{ Disgust } & Valence & ALL: -.102 & $\begin{array}{l}\text { M: .014 } \\
\text { F: .382 }\end{array}$ & $\begin{array}{l}\text { M: }-.051 \\
\text { F: }-.234\end{array}$ & $\begin{array}{l}\text { ALL: } \\
\quad .066\end{array}$ & ALL: -.111 & ALL: .213 & ALL: .166 & ALL: .001 \\
\hline & Arousal & ALL: .116 & $\begin{array}{l}\text { M: } .170 \\
\text { F: }-.313\end{array}$ & $\begin{array}{l}\text { M: .233 } \\
\mathrm{F}: .121\end{array}$ & $\begin{array}{l}\text { ALL: } \\
\quad-.131\end{array}$ & ALL: .020 & ALL: .004 & ALL: -.157 & ALL: .113 \\
\hline & Dominance & ALL: .116 & $\begin{array}{l}\text { M: } .005 \\
\text { F: }-.203\end{array}$ & $\begin{array}{l}\text { M: } .129 \\
\text { F: }-.235\end{array}$ & $\begin{array}{l}\text { ALL: } \\
\quad-.131\end{array}$ & ALL: .020 & ALL: .004 & ALL: .026 & ALL: -.011 \\
\hline & Intensity & ALL: -.005 & $\begin{array}{l}\text { M: }-.026 \\
\mathrm{~F}:-.040\end{array}$ & $\begin{array}{l}\text { M: .142 } \\
\text { F: .002 }\end{array}$ & $\begin{array}{l}\text { ALL: } \\
.259\end{array}$ & ALL: .144 & ALL: -.092 & ALL: .030 & ALL: .268 \\
\hline \multirow[t]{4}{*}{ Sadness } & Valence & ALL: $-.349^{*}$ & $\begin{array}{l}\text { M: }-. \mathbf{5 6 9}^{* *} \\
\text { F: }-.026\end{array}$ & $\begin{array}{l}\text { M: }-.326 \\
\text { F: }-.305\end{array}$ & $\begin{array}{l}\text { ALL: } \\
-.285\end{array}$ & ALL: -.332 & ALL: .130 & ALL: .030 & ALL: -.140 \\
\hline & Arousal & ALL: . 333* & $\begin{array}{l}\text { M: } . \mathbf{. 0 6}^{* *} \\
\text { F: } .252\end{array}$ & $\begin{array}{l}\text { M: .299 } \\
\text { F: } .308\end{array}$ & $\begin{array}{l}\text { ALL: } \\
.219\end{array}$ & ALL: .057 & ALL: - .126 & ALL: -.201 & ALL: .091 \\
\hline & Dominance & ALL: -.290 & $\begin{array}{l}\text { M: .195 } \\
\text { F: } .123\end{array}$ & $\begin{array}{l}\text { M: }-.269 \\
\text { F: }-.094\end{array}$ & $\begin{array}{l}\text { ALL: } \\
-.017\end{array}$ & ALL: -.041 & ALL: .238 & ALL: .271 & ALL: -.031 \\
\hline & Intensity & ALL: .140 & $\begin{array}{l}\text { M: .103 } \\
\text { F: .039 }\end{array}$ & $\begin{array}{l}\text { M: } .125 \\
\text { F: .162 }\end{array}$ & $\begin{array}{l}\text { ALL: } \\
.155\end{array}$ & ALL: .140 & ALL: -.130 & ALL: -.027 & ALL: .128 \\
\hline
\end{tabular}

${ }^{*} p<.05,{ }^{* *} p<.01,{ }^{* * *} p<.001 . \mathrm{M}=$ male participants; $\mathrm{F}=$ female participants. Significant correlations are in bold

aiming to probe verbal emotional processing of sentence contexts.

In keeping with previous studies (e.g., Stevenson et al., 2007), the regression analysis demonstrated that the information provided by dimensional ratings is not the same affective information provided by categorical ratings. Even though categorical intensity ratings were significantly predicted by the dimensional data for all categories, we observed that specific dimensions did not have a significant impact on intensity ratings of the specific categories. These findings indicate that discrete emotions are associated with different weights of the three affective dimensions, at least when they are expressed verbally: where anger and happiness may be better conveyed through the modulation of valence and arousal, sadness may be better conveyed through the modulation of arousal and dominance, and fear may be better conveyed through the modulation of valence and dominance. In other words, the relevance of specific affective dimensions seems to vary as a function of emotional category type. Furthermore, we observed that the level of prediction was the highest for sentences conveying happiness, and lowest for sentences conveying disgust. We should note that the sign of the $\beta$ 
coefficient was positive in the case of valence predicting fear, unlike with the other negative categories, indicating that an increase in valence corresponded to an increase in the intensity ratings of fear sentences. Because sentences expressing fear were perceived as less unpleasant than the other three negative categories, this may explain the specific difference. It is possible that fear is less effectively conveyed through sentences than through pictures or sounds, pointing to the need to consider the effects of stimulus type in the explanation of emotional effects. Although a discussion of the processes or mechanisms underlying the difference between fear and the other negative pictures goes beyond the scope of this article, another possibility is that fear represents a special case of a negative emotion, in line with the assumption that distinct emotional categories are processed by distinct neural substrates (e.g., Calder, Lawrence, \& Young, 2001). This hypothesis should be addressed in future studies.

The heterogeneous effects of the affective dimensions on specific categories lend support to the idea that dimensional and categorical approaches to emotion are not independent, and therefore should be integrated (e.g., Stevenson \& James, 2008; Stevenson et al., 2007). In an attempt to control for as many variables as possible, researchers should take both perspectives into consideration when selecting stimuli for studies on emotion.

Our results also confirmed a consistent finding in the emotion literature - that is, that men and women tend to perceive affective stimuli differently. In keeping with our previous findings (e.g., Soares et al., 2012; Soares et al., 2013, 2015), women rated negative sentences as more pleasant and more arousing, and positive sentences as more pleasant than did men. Also, women provided lower dominance ratings than did men when rating neutral and negative sentences. Furthermore, female participants perceived the sentences as more intense than did male participants, with the exception of angry sentences. In particular, the U-shaped association between valence and arousal was stronger in female than in male participants, showing that women had a stronger disposition to use more extreme arousal scores to rate emotional (vs. neutral) sentences than did men. This finding supports the observation that women tend to show increased defensive and appetitive activation in response to emotional stimuli, with the exception of erotica (e.g., M. M. Bradley et al., 2001; Soares et al., 2015). Possible biological and sociocultural factors may account for the sex differences in the emotional responses to salient stimuli (e.g., Archer, 1996; Ratner, 2000). The observed sex differences suggest that sex-based norms may be more effective when planning stimulus selection in emotion research, and as such, norms for female and male participants separately are provided in the supplementary materials.

Our second study demonstrated that, besides sex, interindividual variability in affective ratings of sentences was also explained by mood and empathy, but not by personality traits. In particular, higher empathy scores were related to more extreme valence scores of both negative and positive, but not of neutral, sentences. Higher empathy scores were also related to increases in the perceived arousal of negative sentences and in the intensity of positive sentences. On the other hand, positive affect correlated with increased arousal of positive sentences. These results suggest that mood and empathy modulate the emotional response to verbal signals, by enhancing the salience or relevance of those signals (see also Schirmer et al., 2008). For example, mood has been shown to act as a modulator of cognitive processes, including how semantic memory is used online (Pinheiro, del Re, Nestor, et al., 2013). Effects of mood congruency may explain the pattern of correlations observed here, that positive mood states were associated with increased perceived arousal of positive (congruent) sentences. This finding is in line with previous studies showing that positive mood states have facilitatory effects on semantic processing (e.g., Chwilla, Virgillito, \& Vissers, 2011; Pinheiro, del Re, Nestor, et al., 2013).

Furthermore, we corroborated the observation that empathy mediates judgments of the emotional states of others in response to both positive and negative events, but not to nonemotional events. The association between empathy scores and the affective ratings of the MAS sentences suggests that comprehending emotional meaning from verbal cues may also involve simulating emotion-expressing actions, or in other words, sharing the joy or distress of others (Perry, Hendler, \& Shamay-Tsoory, 2012), which fits well with embodied theories (e.g., Glenberg, Havas, Becker, \& Rinck, 2005). In keeping with this finding, previous studies have demonstrated that, by mapping the bodily feelings of others onto one's own internal bodily states, increased empathy scores were found to predict reactivity to both positive and negative emotional expressions (e.g., Jabbi, Swart, \& Keysers, 2007; Perry et al., 2012). Furthermore, others have demonstrated that inferring the meaning conveyed by a speaker involves empathizing feelings about the emotional scenarios described in the sentences (e.g., Hagoort, 2013). The association observed in our study may indicate that variability in the responses to emotional verbal meaning reflects differences in empathy.

We also observed that empathic concern and fantasymeasuring the affective dimension of empathy-were higher in female than in male participants, consistent with the previous literature (e.g., Chakrabarti, Bullmore, \& Baron-Cohen, 2006). In particular, we observed that different levels of empathic concern modulated the affective ratings of sentences expressing happiness, sadness, and disgust, but in male participants only. The correlational results raise the interesting possibility that the observed sex differences in affective ratings may be secondary to differences in mood and empathy. Moreover, they underscore the importance of taking into consideration the 
influence of interindividual differences in affective rating studies, and of checking whether the affective norms are well suited to the participant samples (see also Kanske \& Kotz, 2012). In other words, researchers should include measures of individual differences in their analysis of responses to verbal emotional stimuli (e.g., as covariates), rather than relying exclusively on group-averaged responses to these stimuli (e.g., Hamann \& Canli, 2004).

Although our study provided support for moodcongruency effects, there was little support for personalitycongruency effects. This may suggest that the relationship between personality traits and emotional processing is mediated by mood states. Future studies should clarify which aspects of emotion processing are relatively invariant across individuals and which are modulated by individual differences (e.g., Hamann \& Canli, 2004).

\section{Conclusions}

We expect the MAS norms to allow a more controlled and refined selection of sentences as a function of an intended manipulation (e.g., Valence $\times$ Arousal) in emotion research. Similar efforts in characterizing and controlling stimuli according to both dimensional and discrete theories of emotion will contribute to a more thorough understanding of how emotions influence human perception, cognition, and behavior. We believe these norms are a starting point for systematic research on verbal emotional processing with Portuguese-speaking participants, as well as for cross-language comparisons aiming to probe whether and how verbal emotion recognition is shaped by language and culture.

Furthermore, our findings indicate that, in their quest to reveal the neurofunctional underpinnings of emotion processing, researchers should not only consider the influence of sex in the responses to an emotional stimulus, but also of other individual differences that are somewhat modulated by the context, such as empathy and mood states. These two variables should be added to the discussion of how emotionally salient stimuli are perceived and assessed.

\footnotetext{
Author note The authors gratefully acknowledge all the participants who collaborated in the study, and Vera Matos for her help with data acquisition. This work was supported by Grant Numbers IF/00334/ 2012 and PTDC/MHN-PCN/3606/2012, funded by the Portuguese National Science Foundation (Fundação para a Ciência e a Tecnologia [FCT], Portugal) and FEDER (Fundo Europeu de Desenvolvimento Regional) through the European programs QREN (Quadro de Referência Estratégico Nacional) and COMPETE (Programa Operacional Factores de Competitividade), awarded to A.P.P. Additionally, it received support from Grant Number EXPL/MHCPCN/0859/2013, awarded to A.P.S. by FCT and cofunded by FEDER under the PT2020 Partnership Agreement.
}

\section{References}

Anderson, A. (2005). Affective influences on the attentional dynamics supporting awareness. Journal of Experimental Psychology: General, 134, 258-81. doi:10.1037/0096-3445.134.2.258

Archer, J. (1996). Sex differences in social behavior: Are the social role and evolutionary explanations compatible? American Psychologist, 51, 909-917. doi:10.1016/j.yhbeh.2005.07.014

Bayer, M., Sommer, W., \& Schacht, A. (2010). Reading emotional words within sentences: The impact of arousal and valence on eventrelated potentials. International Journal of Psychophysiology, 78, 299-307. doi:10.1016/j.ijpsycho.2010.09.004

Beaucousin, V., Lacheret, A., Turbelin, M. R., More, M., Mazoyer, B., \& Tzourio-Mazoyer, N. (2007). FMRI study of emotional speech comprehension. Cerebral Cortex, 17, 339-352. doi:10.1093/cercor/ bhj151

Belin, P., Fillion-Bilodeau, S., \& Gosselin, F. (2008). The Montreal Affective Voices: A validated set of nonverbal affect bursts for research on auditory affective processing. Behavior Research Methods, 40, 531-539. doi:10.3758/BRM.40.2.531

Bower, G. H. (1981). Mood and memory. American Psychologist, 36, 129-148. doi:10.1016/0005-7967(87)90052-0

Bradley, M. M., Codispoti, M., Sabatinelli, D., \& Lang, P. J. (2001). Emotion and motivation II: Sex differences in picture processing. Emotion, 1, 300-319. doi:10.1037/1528-3542.1.3.300

Bradley, M. M., \& Lang, P. J. (1994). Measuring emotion: The SelfAssessment Manikin and the semantic differential. Journal of Behavior Therapy and Experimental Psychiatry, 25, 49-59. doi: 10.1016/0005-7916(94)90063-9

Bradley, M. M., \& Lang, P. J. (1999). Affective Norms for English Words (ANEW): Stimuli, instruction manual and affective ratings (Technical Report No. C-1). Gainesville: University of Florida, NIMH Center for Research in Psychophysiology. doi:10.1109/ MIC.2008.114

Bradley, M. M., \& Lang, P. J. (2000). Measuring emotion: Behavior, feeling, and physiology. In R. Lane \& L. Nadel (Eds.), Cognitive neuroscience of emotion (pp. 242-276). New York: Oxford University Press.

Bradley, M. M., \& Lang, P. J. (2007). International Affective Digitized Sounds (2nd Edition; IADS-2): Affective ratings of sounds and instruction manual (Technical Report No. B-3). Gainesville: University of Florida, NIMH Center for the Study of Emotion and Attention.

Bradley, B. P., \& Mogg, K. (1994). Mood and personality in recall of positive and negative information. Behaviour Research and Therapy, 32, 137-141. doi:10.1016/0005-7967(94)90095-7

Briesemeister, B. B., Kuchinke, L., Jacobs, A. M., \& Braun, M. (2015). Emotions in reading: Dissociation of happiness and positivity. Cognitive, Affective, \& Behavioral Neuroscience, 15, 287-298. doi:10.3758/s13415-014-0327-2

Briesemeister, B. B., Kuchinke, L., \& Jacobs, A. M. (2011). Discrete emotion norms for nouns: Berlin Affective Word List (DENNBAWL). Behavior Research Methods, 43, 441-448. doi:10.3758/ s13428-011-0059-y

Briesemeister, B. B., Kuchinke, L., \& Jacobs, A. M. (2014). Emotion word recognition: Discrete information effects first, continuous later? Brain Research, 1564, 62-71. doi:10.1016/j.brainres.2014.03.045

Brown, T. A., Chorpita, B. F., \& Barlow, D. H. (1998). Structural relationships among dimensions of the DSM-IV anxiety and mood disorders and dimensions of negative affect, positive affect, and autonomic arousal. Journal of Abnormal Psychology, 107, 179-192. doi: 10.1037/0021-843X.107.2.179

Buchanan, T. W., Lutz, K., Mirzazade, S., Specht, K., Shah, N. J., Zilles, K., \& Jäncke, L. (2000). Recognition of emotional prosody and 
verbal components of spoken language: An fMRI study. Cognitive Brain Research, 9, 227-238. doi:10.1016/S0926-6410(99)00060-9

Burke, L. A., \& James, K. E. (2006). Using online surveys for primary research data collection: Lessons from the field. International Journal of Innovation and Learning, 3, 16-30. doi:10.1504/IJIL. 2006.008177

Calder, A. J., Lawrence, A. D., \& Young, A. W. (2001). Neuropsychology of fear and loathing. Nature Reviews Neuroscience, 2, 352-363. doi:10.1028/35072584

Canli, T., Sivers, H., Whitfield, S. L., Gotlib, I. H., \& Gabrieli, J. D. E. (2002). Amygdala response to happy faces as a function of extraversion. Science, 296, 2191. doi:10.1126/science.1068749

Chakrabarti, B., Bullmore, E., \& Baron-Cohen, S. (2006). Empathizing with basic emotions: Common and discrete neural substrates. Social Neuroscience, 1, 364-384. doi:10.1080/17470910601041317

Chiu, Y. C., Dolcos, F., Gonsalves, B. D., \& Cohen, N. J. (2013). On opposing effects of emotion on contextual or relational memory. Frontiers in Psychology, 4, 103. doi:10.3389/fpsyg.2013.00103

Christie, I. C., \& Friedman, B. H. (2004). Autonomic specificity of discrete emotion and dimensions of affective space: A multivariate approach. International Journal of Psychophysiology, 51, 143153. doi:10.1016/j.ijpsycho.2003.08.002

Chwilla, D. J., Virgillito, D., \& Vissers, C. T. (2011). The relationship of language and emotion: N400 support for an embodied view of language comprehension. Journal of Cognitive Neuroscience, 23, 2400-2414. doi:10.1162/jocn.2010.21578

Cliffordson, C. (2001). Parent's judgments and students' self-judgments of empathy: The structure of empathy and agreement of judgment based on the Interpersonal Reactivity Index (IRI). European Journal of Psychological Assessment, 17, 36-47. doi:10.1027/1015-5759. 17.1.36

Costa, P. T., \& McCrae, R. R. (1992). Normal personality assessment in clinical practice: The NEO Personality Inventory. Psychological Assessment, 4, 5-13. doi:10.1037/1040-3590.4.1.5

Costa, P. T., \& McCrae, R. R. (1994). Set like plaster-Evidence for the stability of adult personality. In T. F. Heatherton \& J. L. Weinberger (Eds.), Can personality change? (pp. 21-40). Washington, DC: American Psychological Association. doi:10.1037/10143-002

Costa, P. T., Terracciano, A., \& McCrae, R. R. (2001). Gender differences in personality traits across cultures: Robust and surprising findings. Journal of Personality and Social Psychology, 81, 322-331. doi:10. 1037/0022-3514.81.2.322

Couper, M. P. (2000). Web surveys: A review of issues and approaches. Public Opinion Quarterly, 64, 1-31. doi:10.1086/318641

Crawford, J. R., \& Henry, J. D. (2004). The positive and negative affect schedule (PANAS): Construct validity, measurement properties and normative data in a large non-clinical sample. British Journal of Clinical Psychology, 43, 245-265. doi:10.1348/0144665031752934

Davis, M. H. (1983). Measuring individual differences in empathy: Evidence for a multidimensional approach. Journal of Personality and Social Psychology, 44, 113-126. doi:10.1037/0022-3514.44.1.113

De Pascalis, V., \& Speranza, O. (2000). Personality effects on attentional shifts to emotional charged cues: ERP, behavioural and HR data. Personality and Individual Differences, 29, 217-238. doi:10.1016/ S0191-8869(99)00189-0

Decety, J., \& Jackson, P. L. (2006). A social-neuroscience perspective on empathy. Psychological Science, 15, 54-58. doi:10.1111/j.09637214.2006.00406.x

Delaney-Busch, N., \& Kuperberg, G. (2013). Friendly drug-dealers and terrifying puppies: Affective primacy can attenuate the N400 effect in emotional discourse contexts. Cognitive, Affective, \& Behavioral Neuroscience, 13, 473-490. doi:10.3758/s13415-013-0159-5

Derntl, B., Finkelmeyer, A., Eickhoff, S., Kellermann, T., Falkenberg, D. I., Schneider, F., \& Habel, U. (2010). Multidimensional assessment of empathic abilities: Neural correlates and gender differences.
Psychoneuroendocrinology, 35, 67-82. doi:10.1016/j.psyneuen. 2009.10.006

Ding, J., Wang, L., \& Yang, Y. (2014). The dynamic influence of emotional words on sentence processing. Cognitive, Affective, \& Behavioral Neuroscience, 15, 55-68. doi:10.3758/s13415-0140315-6

Doerksen, S., \& Shimamura, A. P. (2001). Source memory enhancement for emotional words. Emotion, 1, 5-11. doi:10.1037/1528-3542.1.1.5

Dresler, T., Mériau, K., Heekeren, H. R., \& van der Meer, E. (2009). Emotional Stroop task: Effect of word arousal and subject anxiety on emotional interference. Psychological Research, 73, 364-371. doi:10.1007/s00426-008-0154-6

Ekman, P. (1992). An argument for basic emotions. Cognition and Emotion, 6, 169-200. doi:10.1080/02699939208411068

Ekman, P. (1993). Facial expression and emotion. American Psychologist, 48, 384-392. doi:10.1037/0003-066X.48.4.384

Federmeier, K. D., Kirson, D. A., Moreno, E. M., \& Kutas, M. (2001). Effects of transient, mild mood states on semantic memory organization and use: An event-related potential investigation in humans. Neuroscience Letters, 305, 149-152. doi:10.1016/S0304-3940(01) 01843-2

Fischer, H., Tillfors, M., Furmark, T., \& Fredrikson, M. (2001). Dispositional pessimism and amygdala activity: A PET study in healthy volunteers. NeuroReport, 12, 1635-1638.

Fredrickson, B. L., \& Joiner, T. (2002). Positive emotions trigger upward spirals toward emotional well-being. Psychological Science, 13, 172-175. doi:10.1111/1467-9280.00431

Frith, C. D., \& Frith, U. (1999). Interacting minds-A biological basis. Science, 286, 1692-1695. doi:10.1126/science.286.5445.1692

Galinha, I. C., \& Ribeiro, J. L. P. (2005). Contribuição para o estudo da versão portuguesa da Positive and Negative Affect Schedule (PANAS): II-Estudo psicométrico. Análise Psicológica, 23, 219 227.

Glenberg, A. M., Havas, D., Becker, R., \& Rinck, M. (2005). Grounding language in bodily states: The case for emotion. In D. Pecher \& R. A. Zwaan (Eds.), Grounding cognition: The role of perception and action in memory, language, and thinking (pp. 1-17). New York: Cambridge University Press. doi:10.1017/CBO9780511499968.006

Gomez, A., \& Gomez, R. (2002). Personality traits of the behavioural approach and inhibition systems: Associations with processing of emotional stimuli. Personality and Individual Differences, 32, 1299-1316. doi:10.1016/S0191-8869(01)00119-2

Grandjean, D., Sander, D., Pourtois, G., Schwartz, S., Seghier, M. L., Scherer, K. R., \& Vuilleumier, P. (2005). The voices of wrath: brain responses to angry prosody in meaningless speech. Nature Neuroscience, 8, 145-146. doi:10.1038/nn1392

Grühn, D., \& Scheibe, S. (2008). Age-related differences in valence and arousal ratings of pictures from the International Affective Picture System (IAPS): Do ratings become more extreme with age? Behavior Research Methods, 40, 512-521. doi:10.3758/BRM.40. 2.512

Hadley, C. B., \& MacKay, D. G. (2006). Does emotion help or hinder immediate memory? Arousal versus priority-binding mechanisms. Journal of Experimental Psychology: Learning, Memory, and Cognition, 32, 79-88. doi:10.1037/0278-7393.32.1.79

Hagoort, P. (2013). MUC (memory, unification, control) and beyond. Frontiers in Psychology, 4, 416. doi:10.3389/fpsyg.2013.00416

Haker, H., \& Rössler, W. (2009). Empathy in schizophrenia: Impaired resonance. European Archives of Psychiatry and Clinical Neuroscience, 259, 352-361. doi:10.1007/s00406-009-0007-3

Hamann, S., \& Canli, T. (2004). Individual differences in emotion processing. Current Opinion in Neurobiology, 14, 233-238. doi:10. 1016/j.conb.2004.03.010

Hampson, E., van Anders, S. M., \& Mullin, L. I. (2006). A female advantage in the recognition of emotional facial expressions: Test of an 
evolutionary hypothesis. Evolution and Human Behavior, 27, 401416. doi:10.1016/j.evolhumbehav.2006.05.002

Herbert, C., Junghofer, M., \& Kissler, J. (2008). Event related potentials to emotional adjectives during reading. Psychophysiology, 45, 487498. doi:10.1111/j.1469-8986.2007.00638.x

Holt, D. J., Lynn, S. K., \& Kuperberg, G. R. (2009). Neurophysiological correlates of comprehending emotional meaning in context. Journal of Cognitive Neuroscience, 21, 2245-2262. doi:10.1162/jocn.2008. 21151

Jabbi, M., Swart, M., \& Keysers, C. (2007). Empathy for positive and negative emotions in the gustatory cortex. NeuroImage, 34, 1744 1753. doi:10.1016/j.neuroimage.2006.10.032

Juslin, P. N., \& Laukka, P. (2003). Communication of emotions in vocal expression and music performance: Different channels, same code? Psychological Bulletin, 129, 770-814. doi:10.1037/0033-2909.129. 5.770

Kanske, P., \& Kotz, S. A. (2010). Leipzig Affective Norms for German: A reliability study. Behavior Research Methods, 42, 987-991. doi: 10.3758/BRM.42.4.987

Kanske, P., \& Kotz, S. A. (2011). Cross-modal validation of the Leipzig Affective Norms for German (LANG). Behavior Research Methods, 43, 409-413. doi:10.3758/s13428-010-0048-6

Kanske, P., \& Kotz, S. A. (2012). Auditory affective norms for German: Testing the influence of depression and anxiety on valence and arousal ratings. PLoS ONE, 7, e30086. doi:10.1371/journal.pone. 0030086

Kensinger, E. A., \& Corkin, S. (2003). Memory enhancement for emotional words: Are emotional words more vividly remembered than neutral words? Memory \& Cognition, 31, 1169-1180. doi:10.3758/ BF03195800

Kensinger, E. A., \& Schacter, D. L. (2006). Amygdala activity is associated with the successful encoding of item, but not source, information for positive and negative stimuli. Journal of Neuroscience, 26 , 2564-2570. doi:10.1523/JNEUROSCI.5241-05.2006

Kissler, J., Herbert, C., Peyk, P., \& Junghofer, M. (2007). Buzzwords: Early cortical responses to emotional words during reading. Psychological Science, 18, 475-481. doi:10.1111/j.1467-9280. 2007.01924.x

Kissler, J., Herbert, C., Winkler, I., \& Junghofer, M. (2009). Emotion and attention in visual word processing: An ERP study. Biological Psychology, 80, 75-83. doi:10.1016/j.biopsycho.2008.03.004

Kotz, S. A., Meyer, M., Alter, K., Besson, M., Von Cramon, D. Y., \& Friederici, A. D. (2003). On the lateralization of emotional prosody: An event-related functional MR investigation. Brain and Language, 86, 366-376. doi:10.1016/S0093-934X(02)00532-1

Kousta, S. T., Vinson, D. P., \& Vigliocco, G. (2009). Emotion words, regardless of polarity, have a processing advantage over neutral words. Cognition, 112, 473-481. doi:10.1016/j.cognition.2009.06.007

Kuchinke, L., Jacobs, A. M., Grubich, C., Võ, M. L. H., Conrad, M., \& Herrmann, M. (2005). Incidental effects of emotional valence in single word processing: An fMRI study. Neurolmage, 28, 10221032. doi:10.1016/j.neuroimage.2005.06.050

Lai, V. T., Willems, R. M., \& Hagoort, P. (2015). Feel between the lines: Implied emotion in sentence Comprehension. Journal of Cognitive Neuroscience, 27, 1528-1541. doi:10.1162/jocn_a 00798

Lalande, S., Braun, C. M. J., Charlebois, N., \& Whitaker, H. A. (1992). Effects of right and left hemisphere cerebrovascular lesions on discrimination of prosodic and semantic aspects of affect in sentences. Brain and Language, 42, 165-186. doi:10.1016/0093-934X(92) 90123-V

Lang, P., Bradley, M., \& Cuthbert, B. (2008). International affective picture system (IAPS): Affective ratings of pictures and instruction manual. Gainesville: Center for Research in Psychophysiology, University of Florida. doi:10.1016/j.epsr.2006.03.016
LeDoux, J. E. (1996). The emotional brain: The mysterious underpinnings of emotional life. New York: Simon \& Schuster. doi:10.2307/ 3953278

Lewis, P. A., Critchley, H. D., Rotshtein, P., \& Dolan, R. J. (2007). Neural correlates of processing valence and arousal in affective words. Cerebral Cortex, 17, 742-748. doi:10.1093/cercor/bhk024

Li, H., Yuan, J., \& Lin, C. (2008). The neural mechanism underlying the female advantage in identifying negative emotions: An event-related potential study. NeuroImage, 40, 1921-1929. doi:10.1016/j. neuroimage.2008.01.033

Lima, C. F., \& Castro, S. L. (2011). Speaking to the trained ear: Musical expertise enhances the recognition of emotions in speech prosody. Emotion, 11, 1021-1031. doi:10.1037/a0024521

Lima, C. F., Garrett, C., \& Castro, S. L. (2013). Not all sounds sound the same: Parkinson's disease affects differently emotion processing in music and in speech prosody. Journal of Clinical and Experimental Neuropsychology, 35, 373-392. doi:10.1080/13803395.2013. 776518

Limpo, T., Alves, R. A., \& Castro, S. L. (2010). Medir a empatia: Adaptação portuguesa do Índice de Reactividade Interpessoal. Laboratório Psicologia, 8, 171-184.

Liu, T., Pinheiro, A., Zhao, Z., Nestor, P. G., McCarley, R. W., \& Niznikiewicz, M. A. (2012). Emotional cues during simultaneous face and voice processing: Electrophysiological insights. PLoS ONE, 7, e31001. doi:10.1371/journal.pone.0031001

Lopes, P. N., Brackett, M. A., Nezlek, J. B., Schütz, A., Sellin, I., \& Salovey, P. (2004). Emotional intelligence and social interaction. Personality and Social Psychology Bulletin, 30, 1018-1034. doi: $10.1177 / 0146167204264762$

Lüdtke, J., \& Jacobs, A. M. (2015). The emotion potential of simple sentences: Additive or interactive effects of nouns and adjectives? Frontiers in Psychology, 6, 1137. doi:10.3389/fpsyg.2015.01137

Maddock, R. J., Buonocore, M. H., Kile, S. J., \& Garrett, A. S. (2003). Brain regions showing increased activation by threat-related words in panic disorder. NeuroReport, 14, 325-328. doi:10.1097/01.wnr. 0000059776.23521 .25

Magalhães, E., Salgueira, A., Gonzalez, A. J., Costa, J. J., Costa, M. J., Costa, P., \& Lima, M. P. (2014). NEO-FFI: Psychometric properties of a short personality inventory in Portuguese context. Psicologia: Reflexão e Crítica, 27, 642-657. doi:10.1590/1678-7153. 201427405

Martín-Loeches, M., Fernández, A., Schacht, A., Sommer, W., Casado, P., Jiménez-Ortega, L., \& Fondevila, S. (2012). The influence of emotional words on sentence processing: Electrophysiological and behavioral evidence. Neuropsychologia, 50, 3262-3272. doi:10. 1016/j.neuropsychologia.2012.09.010

Mayer, J. D., McCormick, L. J., \& Strong, S. E. (1995). Mood-congruent memory and natural mood: New evidence. Personality and Social Psychology Bulletin, 21, 736-746. doi:10.1177/0146167295217008

McCrae, R. R., \& Costa, P. T. (2008). The Five-Factor Theory of Personality. In O. P. John, R. W. Robins, \& L. A. Pervin (Eds.), Handbook of personality: Theory and research (3rd ed., pp. 159181). New York: Guilford Press. doi:10.3905/jpe.2000.319978

McCrae, R. R., Costa, P. T., Lima, M. P., Simoes, A., Ostendorf, F., Angleitner, A., ... Piedmont, R. L. (1999). Age differences in personality across the adult life span: Parallels in five cultures. Developmental Psychology, 35, 466-477. doi:10.1103/PhysRevB. 66.085421

Monnier, C., \& Syssau, A. (2008). Semantic contribution to verbal shortterm memory: Are pleasant words easier to remember than neutral words in serial recall and serial recognition? Memory \& Cognition, 36, 35-42. doi:10.3758/MC.36.1.35

Moors, A., Houwer, J., Hermans, D., Wanmaker, S., Schie, K., Harmelen, A.-L., ... Brysbaert, M. (2013). Norms of valence, arousal, dominance, and age of acquisition for 4,300 Dutch words. Behavior Research Methods, 45, 169-177. doi:10.3758/s13428-012-0243-8 
Öhman, A., \& Wiens, S. (2004). The concept of an evolved fear module and cognitive theories of anxiety. In A. S. R. Manstead, N. Frijda, \& A. Fischer (Eds.), Feelings and emotions: The Amsterdam Symposium (pp. 158-173). Cambridge: Cambridge University Press. doi:10.1017/CBO9780511806582

Osgood, C. E., Suci, G. J., \& Tannenbaum, P. H. (1957). The measurement of meaning. Urbana: University Illinois Press.

Ostir, G. V., Smith, P. M., Smith, D., \& Ottenbacher, K. J. (2005). Reliability of the Positive and Negative Affect Schedule (PANAS) in medical rehabilitation. Clinical Rehabilitation, 19, 767-769. doi: $10.1191 / 0269215505 \mathrm{cr} 894 \mathrm{oa}$

Palazova, M., Mantwill, K., Sommer, W., \& Schacht, A. (2011). Are effects of emotion in single words non-lexical? Evidence from event-related brain potentials. Neuropsychologia, 49, 2766-2775. doi:10.1016/j.neuropsychologia.2011.06.005

Paulmann, S., \& Kotz, S. A. (2008a). An ERP investigation on the temporal dynamics of emotional prosody and emotional semantics in pseudo- and lexical-sentence context. Brain and Language, 105, 59-69. doi:10.1016/j.bandl.2007.11.005

Paulmann, S., \& Kotz, S. A. (2008b). Early emotional prosody perception based on different speaker voices. Neuro Report, 19, 209-213. doi: 10.1097/WNR.0b013e3282f454db

Pell, M. D., Jaywant, A., Monetta, L., \& Kotz, S. A. (2011). Emotional speech processing: Disentangling the effects of prosody and semantic cues. Cognition and Emotion, 25, 834-853. doi:10.1080/ 02699931.2010.516915

Perry, D., Hendler, T., \& Shamay-Tsoory, S. G. (2012). Can we share the joy of others? Empathic neural responses to distress vs. joy. Social Cognitive and Affective Neuroscience, 7, 909-916. doi:10.1093/ scan/nsr073

Pinheiro, A. P., del Re, E., Mezin, J., Nestor, P. G., Rauber, A., McCarley, R. W., ... Niznikiewicz, M. A. (2013). Sensory-based and higherorder operations contribute to abnormal emotional prosody processing in schizophrenia: An electrophysiological investigation. Psychological Medicine, 43, 603-618. doi:10.1017/ S003329171200133X

Pinheiro, A. P., del Re, E., Nestor, P. G., McCarley, R. W., Gonçalves, O. F., \& Niznikiewicz, M. (2013). Interactions between mood and the structure of semantic memory: Event-related potentials evidence. Social Cognitive and Affective Neuroscience, 8, 579-594. doi:10. 1093/scan/nss035

Pinheiro, A. P., Rezaii, N., Rauber, A., Liu, T., Nestor, P. G., McCarley, R. W., ... Niznikiewicz, M. A. (2014). Abnormalities in the processing of emotional prosody from single words in schizophrenia. Schizophrenia Research, 152, 235-241. doi:10.1016/j.schres.2013. 10.042

Pinheiro, A. P., Vasconcelos, M., Dias, M., Arrais, N., \& Gonçalves, O. F. (2015). The music of language: An ERP investigation of the effects of musical training on emotional prosody processing. Brain and Language, 140, 24-34. doi:10.1016/j.bandl.2014.10.009

Posner, J., Russell, J. A., Gerber, A., Gorman, D., Colibazzi, T., Yu, S., ... Peterson, B. S. (2009). The neurophysiological bases of emotion: An fMRI study of the affective circumplex using emotion-denoting words. Human Brain Mapping, 30, 883-895. doi:10.1002/hbm. 20553

Raposo, A., Vicens, L., Clithero, J. A., Dobbins, I. G., \& Huettel, S. A. (2011). Contributions of frontopolar cortex to judgments about self, others and relations. Social Cognitive and Affective Neuroscience, 6 , 260-269. doi: $10.1093 / \mathrm{scan} / \mathrm{nsq} 033$

Ratner, C. (2000). A cultural-psychological analysis of emotions. Culture and Psychology, 6, 5-39. doi:10.1177/1354067X0061001

Redondo, J., Fraga, I., Padrón, I., \& Comesaña, M. (2007). The Spanish adaptation of ANEW (affective norms for English words). Behavior Research Methods, 39, 600-605. doi:10.3758/BF03193031

Riegel, M., Wierzba, M., Wypych, M., Żurawski, Ł., Jednoróg, K., Grabowska, A., \& Marchewka, A. (2015). Nencki Affective Word
List (NAWL): The cultural adaptation of the Berlin Affective Word List-Reloaded (BAWL-R) for Polish. Behavior Research Methods, 47, 1222-1236. doi:10.3758/s13428-014-0552-1

Russell, J. A. (2003). Core affect and the psychological construction of emotion. Psychological Review, 110, 145-172. doi:10.1037/0033295X.110.1.145

Rusting, C. L. (1998). Personality, mood, and cognitive processing of emotional information: Three conceptual frameworks. Psychological Bulletin, 124, 165-196. doi:10.1037/0033-2909. 124.2.165

Rusting, C. L., \& Larsen, R. J. (1998). Personality and cognitive processing of affective information. Personality and Social Psychology Bulletin, 24, 200-213. doi:10.1177/0146167298242008

Schacht, A., \& Sommer, W. (2009). Emotions in word and face processing: Early and late cortical responses. Brain and Cognition, 69, 538550. doi:10.1016/j.bandc.2008.11.005

Scherer, K. R. (1995). Expression of emotion in voice and music. Journal of Voice, 9, 235-248. doi:10.1016/S0892-1997(05)80231-0

Scherer, K. R., \& Ellgring, H. (2007). Are facial expressions of emotion produced by categorical affect programs or dynamically driven by appraisal? Emotion, 7, 113-130. doi:10.1037/1528-3542.7.1.113

Schirmer, A., Escoffier, N., Zysset, S., Koester, D., Striano, T., \& Friederici, A. D. (2008). When vocal processing gets emotional: On the role of social orientation in relevance detection by the human amygdala. NeuroImage, 40, 1402-1410. doi:10.1016/j.neuroimage. 2008.01.018

Schirmer, A., Kotz, S. A., \& Friederici, A. D. (2002). Sex differentiates the role of emotional prosody during word processing. Cognitive Brain Research, 14, 228-233. doi:10.1016/S0926-6410(02)001088

Scott, G. G., O’Donnell, P. J., Leuthold, H., \& Sereno, S. C. (2009). Early emotion word processing: Evidence from event-related potentials. Biological Psychology, 80, 95-104. doi:10.1016/j.biopsycho.2008. 03.010

Scott, S. K., Young, A. W., Calder, A. J., Hellawell, D. J., Aggleton, J. P., \& Johnsons, M. (1997). Impaired auditory recognition of fear and anger following bilateral amygdala lesions. Nature, 385, 254-257. doi: $10.1038 / 385254 \mathrm{a} 0$

Shamay-Tsoory, S. G., Aharon-Peretz, J., \& Perry, D. (2009). Two systems for empathy: A double dissociation between emotional and cognitive empathy in inferior frontal gyrus versus ventromedial prefrontal lesions. Brain, 132, 617-627. doi:10.1093/brain/awn279

Singer, T., Seymour, B., O’Doherty, J., Dolan, R. J., Kaube, H., \& Frith, C. D. (2004). Empathy for pain involves the affective but not sensory components of pain. Science, 303, 1157-1162. doi:10.1126/ science. 1093535

Soares, A. P., Comesaña, M., Pinheiro, A. P., Simões, A., \& Frade, C. S. (2012). The adaptation of the Affective Norms for English Words (ANEW) for European Portuguese. Behavior Research Methods, 44, 256-269. doi:10.3758/s13428-011-0131-7

Soares, A. P., Iriarte, Á., Almeida, J. J. D., Simões, A., Costa, A., França, P., ... Comesaña, M. (2014). Procura-PALavras (P-PAL): A new measure of word frequency for contemporary European Portuguese. Psicologia: Reflexão e Crítica, 27, 110-123. doi:10. 1590/S0102-79722014000100013

Soares, A. P., Pinheiro, A. P., Costa, A., Frade, C. S., Comesaña, M., \& Pureza, R. (2013). Affective auditory stimuli: Adaptation of the International Affective Digitized Sounds (IADS-2) for European Portuguese. Behavior Research Methods, 45, 1168-1181. doi:10. 3758/s13428-012-0310-1

Soares, A. P., Pinheiro, A. P., Costa, A., Frade, C. S., Comesaña, M., \& Pureza, R. (2015). Adaptation of the International Affective Picture System (IAPS) for European Portuguese. Behavior Research Methods, 47, 1159-1177. doi:10.3758/s13428-014-0535-2

Stevenson, R. A., \& James, T. W. (2008). Affective auditory stimuli: Characterization of the International Affective Digitized Sounds 
(IADS) by discrete emotional categories. Behavior Research Methods, 40, 315-321. doi:10.3758/BRM.40.1.315

Stevenson, R. A., Mikels, J. A., \& James, T. W. (2007). Characterization of the Affective Norms for English Words by discrete emotional categories. Behavior Research Methods, 39, 1020-1024. doi:10. 3758/BF03192999

Stormark, K. M., Nordby, H., \& Hugdahl, K. (1995). Attentional shifts to emotionally charged cues: Behavioural and ERP data. Cognition and Emotion, 9, 507-523. doi:10.1080/02699939508408978

Võ, M. L.-H., Conrad, M., Kuchinke, L., Urton, K., Hofmann, M. J., \& Jacobs, A. M. (2009). The Berlin Affective Word List Reloaded (BAWL-R). Behavior Research Methods, 41, 534-538. doi:10. 3758/BRM.41.2.534

Wallbott, H. G. (1998). Bodily expression of emotion. European Journal of Social Psychology, 28, 879-896. doi:10.1002/(SICI)10990992(1998110)28:6<879::AID-EJSP901>3.0.CO;2-W

Warriner, A. B., Kuperman, V., \& Brysbaert, M. (2013). Norms of valence, arousal, and dominance for 13,915 English lemmas. Behavior Research Methods, 45, 1191-1207. doi:10.3758/s13428-012-0314-x
Watson, D., \& Tellegen, A. (1985). Toward a consensual structure of mood. Psychological Bulletin, 98, 219-235. doi:10.1037/00332909.98.2.219

Wierzba, M., Riegel, M., Wypych, M., Jednoróg, K., Turnau, P., Grabowska, A., \& Marchewka, A. (2015). Basic emotions in the Nencki Affective Word List (NAWL BE): New method of classifying emotional stimuli. PLoS ONE, 10, e0132305. doi:10.1371/ journal.pone. 0132305

Willems, R. M., Clevis, K., \& Hagoort, P. (2011). Add a picture for suspense: Neural correlates of the interaction between language and visual information in the perception of fear. Social Cognitive and Affective Neuroscience, 6, 404-416. doi:10.1093/scan/nsq050

Wirth, M., Horn, H., Koenig, T., Stein, M., Federspiel, A., Meier, B., ... Strik, W. (2007). Sex differences in semantic processing: Eventrelated brain potentials distinguish between lower and higher order semantic analysis during word reading. Cerebral Cortex, 17, 19871997. doi:10.1093/cercor/bhl121

Wittfoth, M., Schröder, C., Schardt, D. M., Dengler, R., Heinze, H. J., \& Kotz, S. A. (2010). On emotional conflict: Interference resolution of happy and angry prosody reveals valence-specific effects. Cerebral Cortex, 20, 383-392. doi:10.1093/cercor/bhp106 